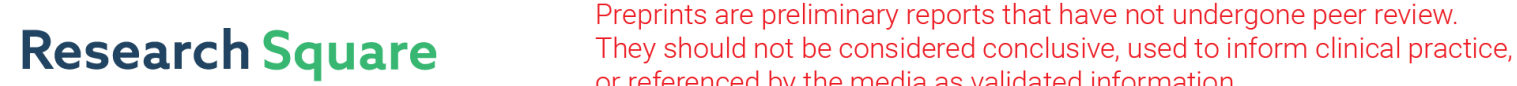 or referenced by the media as validated information. \\ Retrieval of Land Surface Temperature From \\ Landsat 8 Data of the Dandong-liaoyang Geothermal Area
}

\section{Yiming Luan ( $1505029440 @ q q . c o m$ )}

College of Earth Sciences, Jilin University, Changchun 130061, China;

\section{Research}

Keywords: land surface temperature, atmospheric correction, geothermal area, Landsat 8, Remote Sensing

Posted Date: September 25th, 2020

DOI: https://doi.org/10.21203/rs.3.rs-80651/v1

License: (ㅇ (i) This work is licensed under a Creative Commons Attribution 4.0 International License.

Read Full License 


\title{
Retrieval of Land Surface Temperature from Landsat 8 Data of the Dandong-Liaoyang Geothermal Area
}

\author{
Jinxin He ${ }^{1,}{ }^{*}$, Yiming Luan ${ }^{1}$, Wenqing $\mathrm{Li}^{1}{ }^{1} \mathrm{Ning} \mathrm{Ma}^{1}$, Huanzhao Sun ${ }^{1}$ \\ 1 College of Earth Sciences, Jilin University, Changchun 130061, China; \\ hejx@jlu.edu.cn (J.H.); 1505029440@qq.com(Y.L.); liwq@jlu.edu.cn (W.L.); \\ 1639911794@qq.com(N.M.);313823338@qq.com (H.S.) \\ * Correspondence: hejx@jlu.edu.cn; Tel.: +86-431-8850-2327 (J.H.)
}

\begin{abstract}
In recent years, with the intensification of problems like the depletion of traditional fossil fuels and environmental degradation, the development of new energy sources has become a key long-term strategy in China. Geothermal energy has attracted much attention due to its advantages of abundance and low environmental impact. Based on infrared data sensed remotely by the Landsat 8 satellite, this paper reports a verification of the atmospheric-correction method for extracting the surface temperature of the Dandong-Liaoyang geothermal region in all months of 2014. The method combines the abnormal points in the inversion results with the local sites of hot springs, structures, local historical air temperatures, and land surface temperature/emissivity data (MOD11_L2). Results showed that these data sources were spatially distributed in similar ways, which indicates that these results can be used to identify promising geothermal resources from publically available thermal-infrared remote-sensing data.
\end{abstract}

Keywords: land surface temperature; atmospheric correction; geothermal area; Landsat 8; Remote Sensing

\section{Introduction}

In recent years, as fossil fuels are growing scarce, researchers have become focused on finding more-reliable and sustainable energy resources. Geothermal energy is both reliable and sustainable and does not emit pollutants. The economically rational exploitation of geothermal resources can address the social challenges of multiple resource constraints and heavy environmental pressure [1-2]. Land surface temperature (LST) is a very important indicator in the exploration for geothermal resources. By identifying differences in thermal remote sensing data, researchers can identify the location and quantities of available geothermal resources. To obtain the spatial and temporal distribution of the surface temperature over the whole earth range or large regions, only thermal-infrared remote sensing data can be used. Thermal-infrared remote sensing data is collected from satellites or aircraft with sensors that use bands limited to infrared wavelengths emitted from objects on the surface. This data is correlated with objects and can then be used to infer the surface 
temperature. At present, many satellites in orbit carry thermal-infrared sensors, such as AVHRR, ASTER, MODIS, Landsat TM/ETM+, and Landsat 8 thermal-infrared sensor (TIRS). The rapid development of thermal-infrared geothermal retrieval technology allows the quantitative study of thermal resources and monitoring of changes in the distribution of small thermal fields. These data sources are characterized by high speed, low cost, and wide range. This breadth of data and analysis techniques has laid a solid technical foundation for the application of remote sensing technology to the exploration of geothermal resources. In recent years, several methods to infer surface temperature using thermal-infrared remote sensing data have come to prominence: the split-window algorithm [3]; the mono-window algorithm [4-6]; the multiple-channels algorithm [7-8]; the atmospheric-correction method (thermal channel method) [9-10].

The Dandong-Liaoyang region is in the east of Liaoning province, China, which is rich in geothermal resources and has a well-developed infrastructure. More than 20 hot springs are known in this area, including the famous Dongtang and Wulongbei springs, so the area has good contrast for testing the analysis of thermal-infrared remote sensing data. The thermal-infrared remote sensing data is selected by Landsat 8 data. The Landsat 8 satellite has an advanced TIRS with a spatial resolution of $30 \mathrm{~m}$. Below, we report how we used the Landsat 8 thermal-infrared remote sensing data to compare the anomalous areas in the extracted surface temperature map with the spatial distribution of fault structures and known hot spring locations in the study area. This comparison gives evidence for the effectiveness of the temperature-retrieval method. Below, the temperature retrieval results are also compared with LST data from the National Aeronautics and Space Administration's (NASA) MODIS LST and Emissivity dataset (MOD11-L2), the distribution of fault zones and hot springs.

The rest of this paper is organized as follows: the section 2 introduces the geographic, geological, and geothermal characteristics of the study area; section 3 details our method for extracting LST from Landsat 8 data; section 4 discusses our comparative method to verify the accuracy of the retrieval algorithm; and section 5 concludes the paper.

\section{Study Area}

\subsection{Geography}

The study area is the eastern part of Liaoning Province, China (Figure 1), an administrative region mainly in the Dandong, Liaoyang and Fengcheng jurisdictions, with geographical coordinates: longitude $123^{\circ} 00$ ' $\sim 125^{\circ} 00^{\prime}$ East, latitude $40^{\circ} 00^{\prime} \sim 41^{\circ} 10^{\prime}$ North. The area covers about 20,000 square kilometers and has convenient transportation, railway, and highway infrastructure. The North Korea - Dandong - Shenyang international railway traverses the survey area from south to north. The main highways are the Shenyang Dandong expressway and the Hegang - Dandong - Dalian line, Dandong - Holing line. In addition, each city, county, and town is connected with some roads. Resources and material can be moved through the Dandong Langtou port and the Dandong Langtou International airport. 


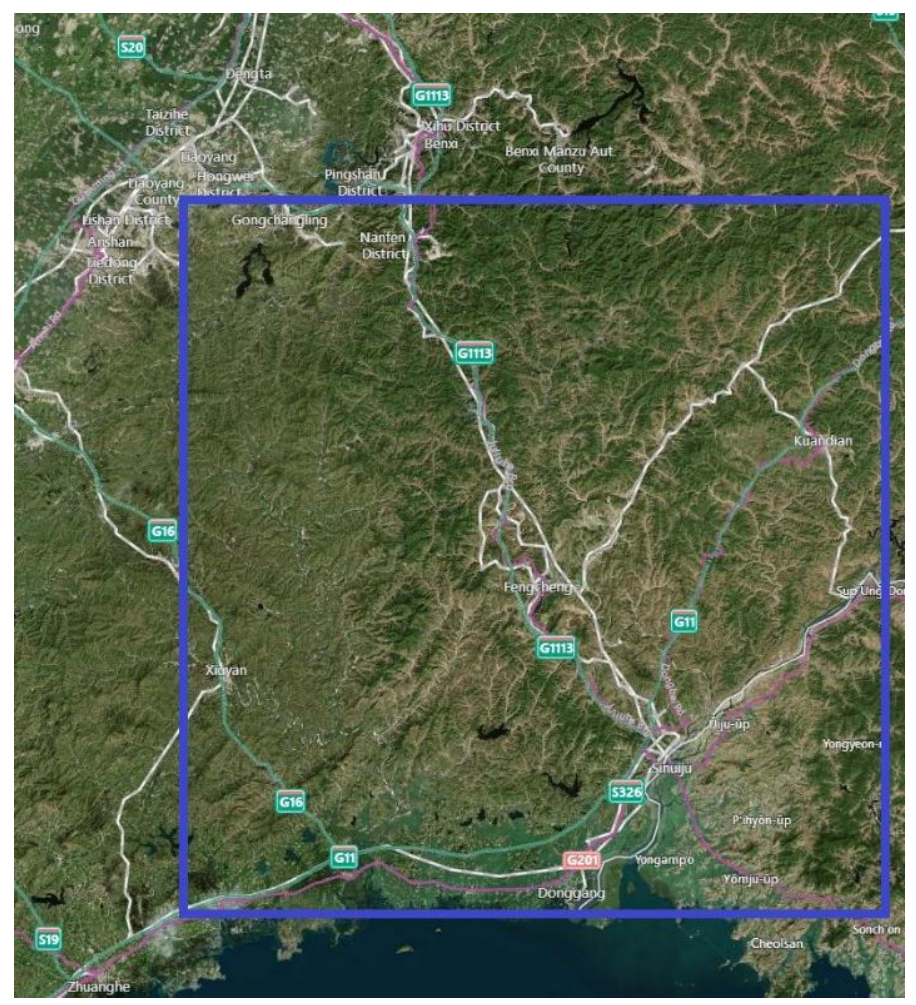

Figure 1. Location of the study area is shown in blue box.

The geomorphology of the survey area is complex and mostly mountainous. The north part belongs to the hilly region of eastern Liaoning, which is the western extension of the Changbai Mountain range. The vegetation is lush, especially in summer. The topography is complex and varied, and the height difference between peaks is also very large. Most of the peaks are between 500-700 meters above sea level, and the highest peak is about 1180 meters above sea level. The south of this region features low hills and a coastal plain, with an elevation below 500 meters. The main mineral resources are gold, silver, lead, zinc, boron, iron boride, magnesite, iron, copper, pyrite, talc, jade, and limestone in more than 18 forms.

\subsection{Geology}

As Figure 2 shows, the Dandong-Liaoyang area is to the north of the China platform of the Jiaoliao belt, to the south of the Longgang block, and the west of the Liaoji rift. The eastern side of Tan-Lu fault zone lies under this region, and the main fault and branch faults of Tan-Lu fault all pass through the study area, spanning three four-level tectonic units, namely the Chengzitan fault block, Fengcheng uplift, and the Liaoyang-Benxi depression [11]. The crust in the study area is a binary structure with distinct base and cap, and its crystalline basement is widely exposed in the area, which is mainly composed of the Archean metamorphic pluton and Paleoproterozoic Liaohe groups. Caprock is exposed sporadically, mainly including Neoproterozoic, Paleozoic terrestrial clastic rocks, carbonate rocks, Mesozoic river and lake facies, and continental volcano-sedimentary series [12]. The study area, which is still in the active stage after many tectonic evolutions, features three large structure faults trending in the NNE, NE, and NW directions. 


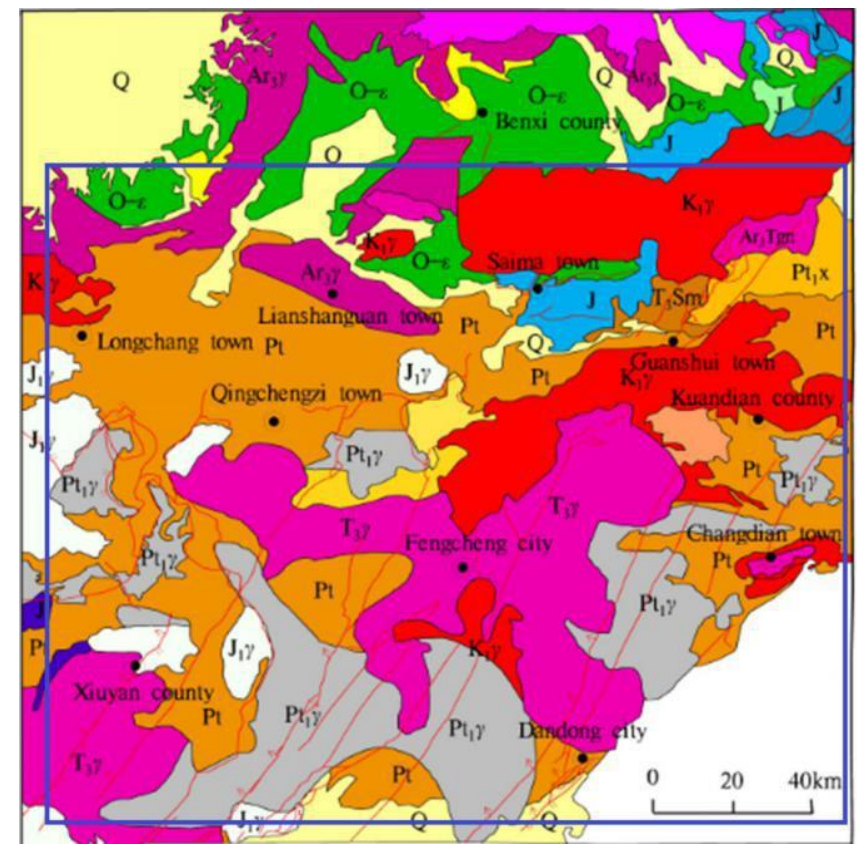

Figure 2. Regional stratigraphy of the study area is shown in blue box. (Reproduced with permission from Li, 2015)

\subsection{Geothermal characteristics}

Due to the development of branching faults and the breakage of the crust structure, surface water can easily infiltrate deep underground, where it is heated and then rises to the surface to form hot springs. As Figure 3 shows, the study area in the eastern region has many hot spots. These are known to have several large hot springs, with spring water temperatures between $30^{\circ} \mathrm{C}-71^{\circ} \mathrm{C}$, which are relatively medium or low temperatures for hot springs. They are generally distributed in the NNE and NE of the Liaodong region. Geothermal activity is driven by major faults; most geothermal fields are located at the intersection of fault structures. Many geothermal fields have been found in the study area, most of which are exposed in the form of hot springs. These hot springs are mainly fed by bedrock fissure water and are distributed mainly in the mountainous uplift area. According to previous data, the NNE and NE fault zones formed in the Indosin-Yanshan period are the main thermal conductivity structures that control the heat storage in the study area, and the thermal storage rocks are mainly Mesozoic granite [13]. 


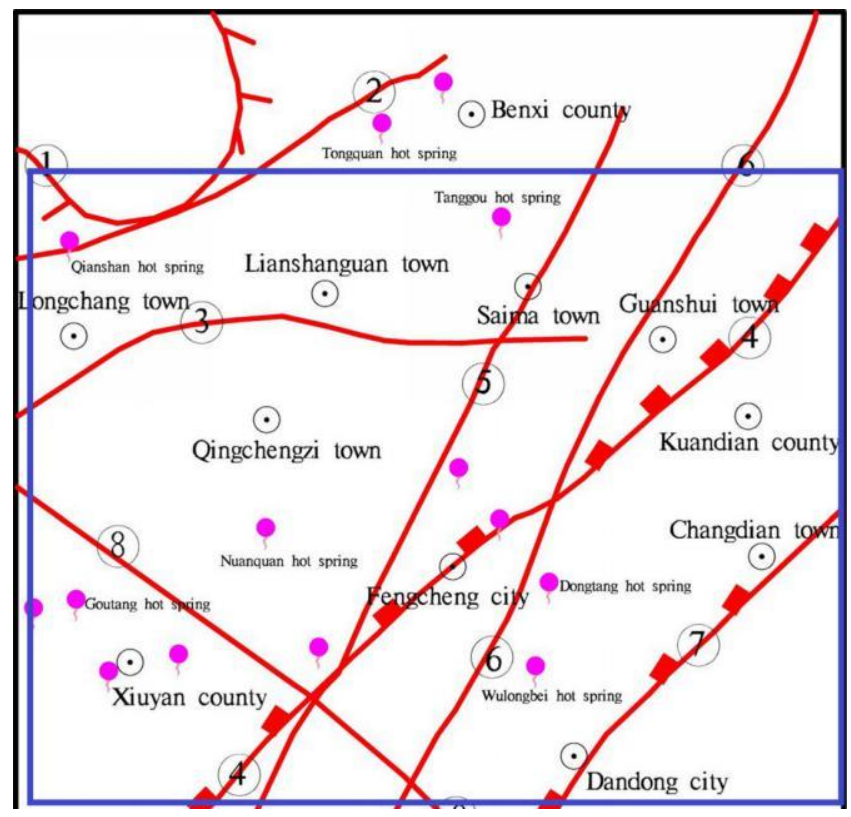

Figure 3. Geothermal characteristics of the study area is shown in blue box.

(Reproduced with permission from Li, 2015)

In sum, the study area includes several active tectonic belts with faults, which provide channels for the formation of hot springs, and a large amount of Mesozoic granite rock serves as thermal storage media that provide stable and reliable sources of heat. These previously identified resources suggest that the study area is ripe for the development of geothermal energy plants [13].

\section{Methods}

Since the study area has four distinct seasons, with severe vegetation cover in summer and severe snow cover in winter, a suitable time and phase should be chosen when considering the selection of remote-sensing data for our analysis. Landsat 8 thermal-infrared remote sensing data from each month of 2014 was selected in this paper for reasons of accuracy, acquisition speed, and clear boundaries. After a review of previously discussed surface-temperature retrieval algorithms, we chose the atmospheric-correction method (also known as the heat-radiation-transfer equation algorithm) to infer surface temperature. ArcGIS 10.1 and ENVI 5.1 software were used for comprehensive data analysis. A basic flow chart of our analysis is shown in Figure 4: 


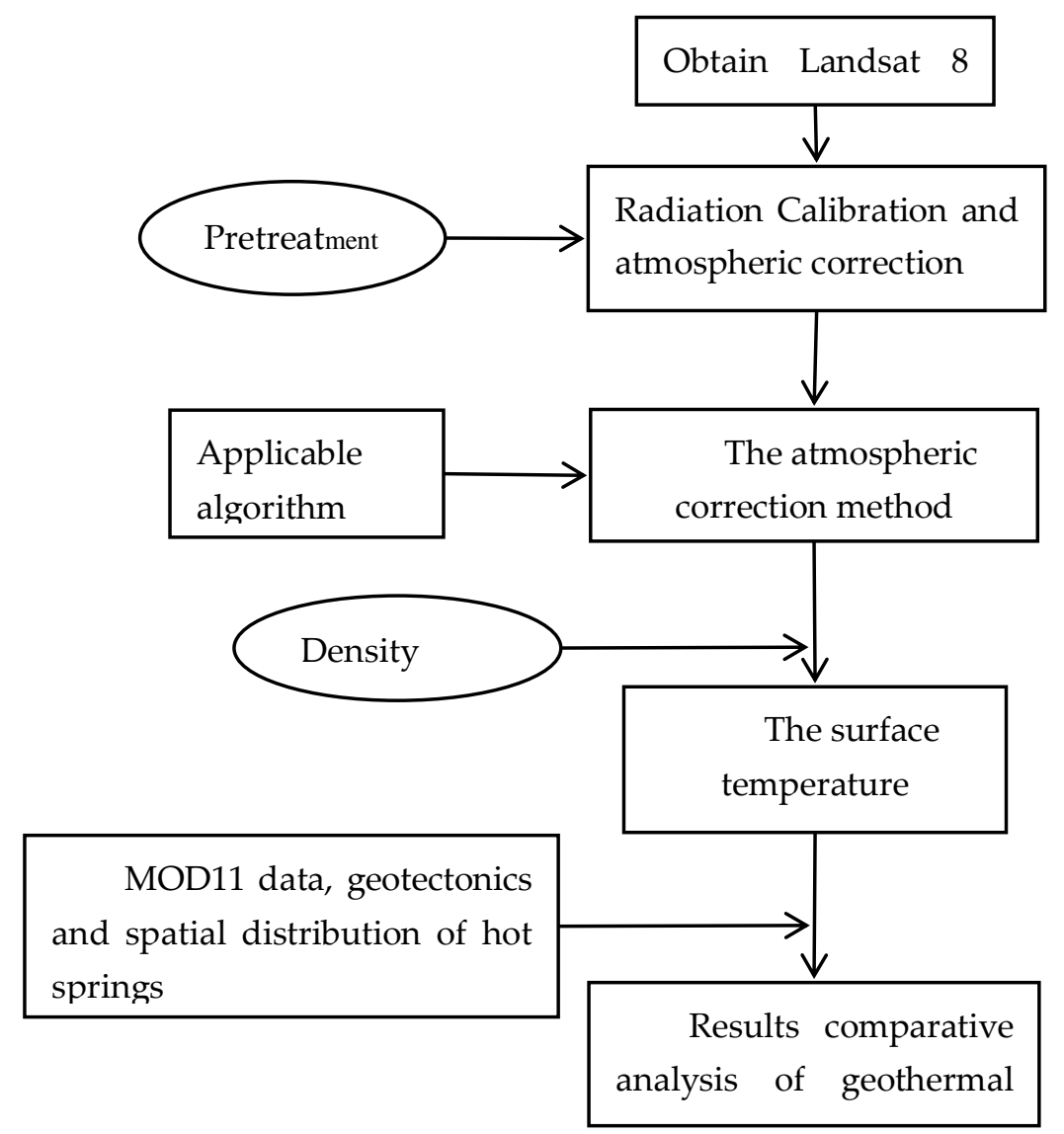

Figure 4. Basic flow chart.

\subsection{Landsat 8 data preprocessing}

NASA successfully launched the new series of Landsat satellites on February 11, 2013. Landsat 8 increases the previous number of sensor bands and improves dramatically on the near-infrared band. The Landsat 8 satellite has two main sensors: OLI (Operational Land Imager) and TIRS. OLI was developed by Ball Aerospace \& Technologies Corp in Colorado; TIRS was mainly designed at NASA's Goddard Space Flight Center [14]. Landsat 8 is expected to be in service for more than 5 years. TIRS data is used in this article. This instrument uses a quantum point infrared photon detector to detect longer wavelengths of radiation reflected from the earth. The intensity of the signal is correlated with the surface temperature. The new technology of a quantum-well infrared photodetector is used in the sensor and is more sensitive and less expensive than previous technologies [15-16].

To use the spectral information from the remote sensing images effectively, the radiation intensities need to be calibrated. For the Landsat 8 data, the ENVI software includes an automatic calibration tool. Since the purpose of radiometric calibration in geothermal retrieval is to convert $\mathrm{DN}$ value to radiance values, we opened the radiometric calibration settings in the toolbox and changed the calibration type to radiance. When other default parameters are selected, the tool will deliver Band10 radiance images. If the Landsat 8 is marked with L1T when downloaded, it indicates that the data has undergone geometric correction with topographic features at the time of acquisition, and can generally be used directly. 


\subsection{LST retrieval}

Using the basic principles of radiative transfer equations for the temperature retrieval, an atmospheric model is used to simulate the relevant influences of the atmosphere. First, the algorithm estimates the atmosphere's effects on thermal radiation or absorption transfer at the surface. Next, that part of the total thermal radiation detected by the sensor is eliminated, then the thermal radiation intensity from the surface is calculated, and finally, this intensity is converted to temperatures using the ENVI software kit [17-18]. The details of this process are given in a flowchart in Figure 5.

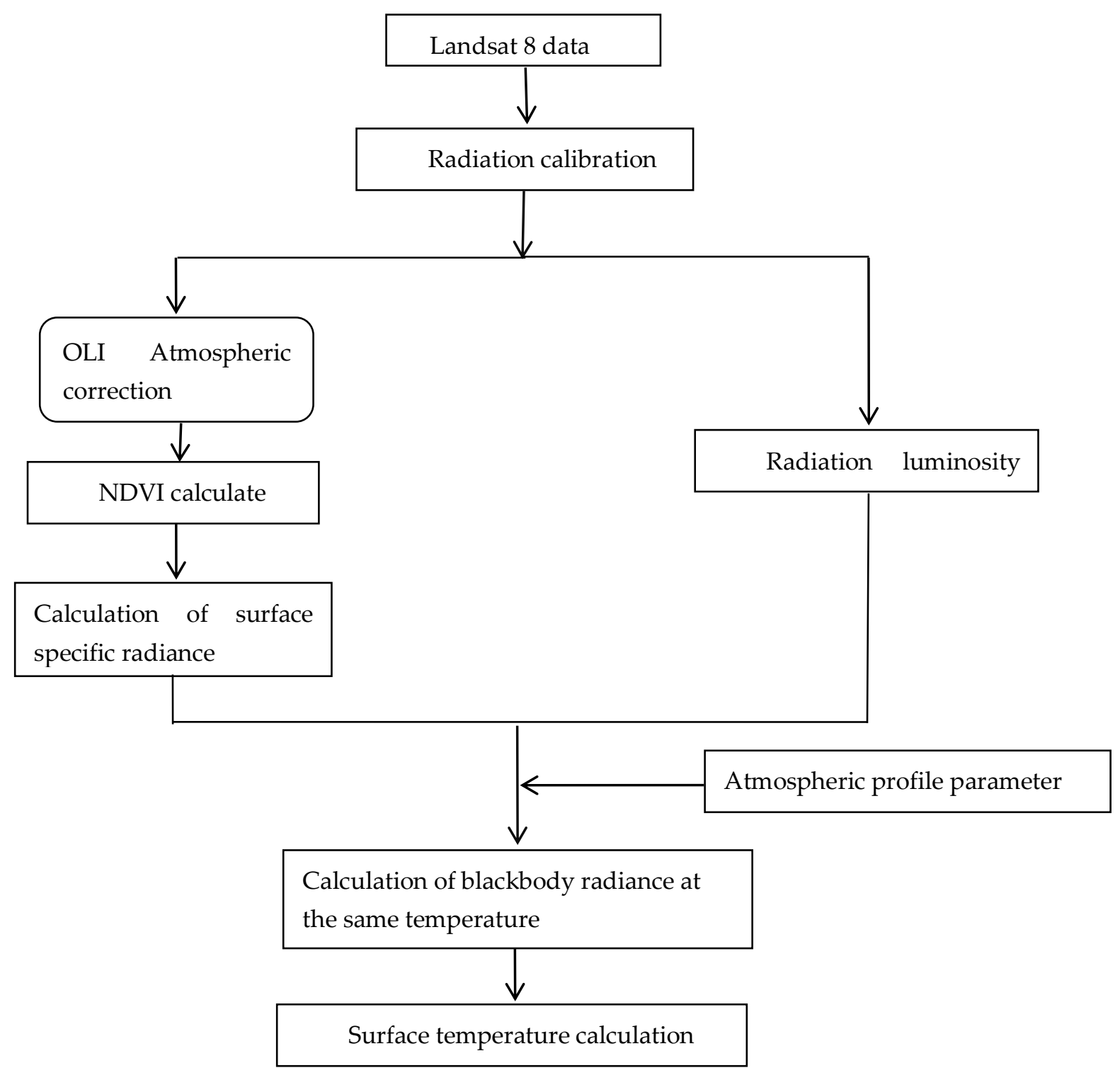

Figure 5. Landsat 8 surface-temperature retrieval flow chart based on atmospheric correction.

As radiation is transmitted from the earth through atmospheric gases, the infrared radiation energy value $\mathrm{L} \lambda_{\lambda}$ measured by the satellite is composed of three main parts: the actual radiative brightness from the ground that passes through the atmosphere to the satellite sensor; upwelling radiance $L \uparrow$, and descending radiance $L \downarrow$. The formula is as follows: 


$$
L_{\lambda}=\left[\varepsilon B\left(T_{S}\right)+(1-\varepsilon) L \downarrow\right] \tau+L \uparrow
$$

$\varepsilon$ is the land surface emissivity; B $(T s)$ is the blackbody radiance; $T_{s}$ is the LST temperature $[\mathrm{K}]$; and $\tau$ is the atmospheric transmittance.

The formula for $\mathrm{B}(\mathrm{TS})$ is:

$$
B\left(T_{S}\right)=\left[L_{\lambda}-L \uparrow-\tau(1-\varepsilon) L \downarrow\right] / \tau \varepsilon
$$

The three basic parameters, atmospheric transmittance, upwelling radiance, and descending radiance, must be obtained using the Atmospheric Correction Parameter Calculator in NASA (https://atmcorr.gsfc.nasa.gov/); the imaging time of the remote sensing data and the central latitude and longitude of the downloaded image are input to retrieve the radiance data at that time and place.

The surface emissivity is calculated with the band-math tool in the ENVI software. After estimating the brightness of blackbody radiation corresponding to the surface temperature, the real surface temperature can be obtained according to Planck's law. The formula is as follows:

$$
T_{S}=\mathrm{K}_{2} / \ln \left(\mathrm{K}_{1} / B\left(T_{S}\right)+1\right)
$$

$\mathrm{K}_{1}$ and $\mathrm{K}_{2}$ are two constants whose values can be retrieved from the Landsat 8 files. For band 10 in the TIRS data, $\mathrm{K}_{1}=774.89 \mathrm{~W} /\left(\mathrm{m}^{2} \bullet \mu \mathrm{m} \bullet \mathrm{sr}\right) ; \mathrm{K}_{2}=1321.08 \mathrm{~K}$.

\subsection{Calculation of normalized vegetation index and specific radiation rate from the surface}

This paper adopts the same method for calculation of the surface specific radiation rate as TM/ETM+6 (because the Landsat 8 Band10 band has similar spectral range as the $\mathrm{TM} / \mathrm{ETM}+6$ thermal-infrared bands) [19-20]. The specific radiation rate from the surface is estimated based on the weighted mixed model of land-cover types proposed by [10], which uses the following formula:

$$
\varepsilon=0.004 P v+0.986
$$

$P_{v}$ represents vegetation coverage, calculated as:

$$
P_{v}=\left[\left(N D V I-N D V I_{S}\right) /\left(N D V I_{V}-N D V I_{S}\right)\right]
$$

NDVIv is the total vegetation cover index and NDVIs is the vegetation cover index for bare ground. Generally, the simple vegetation calculation model is adopted for calculation. Empirically, the total vegetation index for our study area is 0.70 , and the total bare-ground vegetation index is 0.05 . In other words, this expression can be understood as stating that when the NDVI of a pixel in an image is greater than $0.70, P_{v}$ is 1 , which means that the pixel area is in a region covered by dense vegetation and no bare soil can be seen. When the NDVI is less than 0.05 and $P_{v}$ is 0 , the pixel area is completely bare, without any vegetation coverage. In the ENVI band-math tool, the formula is:

(b1 gt 0.7$) * 1+($ b1 lt 0.05$) * 0+($ b1 ge 0.05 and b1 le 0.7$) *(($ b1 -0.05$) /(0.7-0.05))$ 
b1 is a numerical image of NDVI, and the image of vegetation coverage $\left(\mathrm{P}_{\mathrm{v}}\right)$ is obtained after using the band-math tool, with values between 0 and 1 . The surface-emissivity image can be obtained with the continuous-input expressions in the band-math tool.

\subsection{Blackbody radiation and surface temperature calculation}

The radiance calculation formula implemented in the band-math tool is:

$$
(\mathrm{b} 2-\mathrm{a} 1-\mathrm{a} 2 *(1-\mathrm{b} 1) * \mathrm{a} 3) /(\mathrm{a} 2 * \mathrm{~b} 1)
$$

The variables b1 represent the numerical image of the surface's specific emissivity, b2 is the radiation brightness numerical image of the 10th band after calibration, a1 is the brightness of upwelling radiance taken from NASA data, a2 is the transmittance of the atmosphere in the thermal-infrared band, a3 is the descending radiance. The radiance image of a blackbody at the same temperature is calculated.

When all the relevant parameters are obtained, Planck's law can be used to calculate the surface temperature. Since the calculated temperature is in Kelvin temperature, 273.15 is subtracted to return the temperature in Celsius.

\subsection{Image mosaic}

As the study area is not covered by a single Landsat 8 image, multiple remote sensing images must be mosaicked together, and the study area is cropped from the resulting mosaic. The seamless mosaic scripts built into the ENVI software allow users to combine multiple non-geographic images into a larger single image. The resulting image is not too stiff for radiation calibration and introduces no error to the results.

The simple process of mosaicking is performed by the seamless mosaic tool in ENVI software: 1. Data loading; 2. Color correction; 3. Seamlines/feathering; 4. Export. We especially found that, although the color correction and add-seam-lines operations can make the mosaic images match better and can prevent bad pixels at the contact edges, these two operations will change the original DN values in the images, and this may cause serious errors in the retrieval of surface temperature. Thus, the above operations were not applied. Taking September 1, 2014, as an example, the result after mosaicking is shown in Figure 6: 


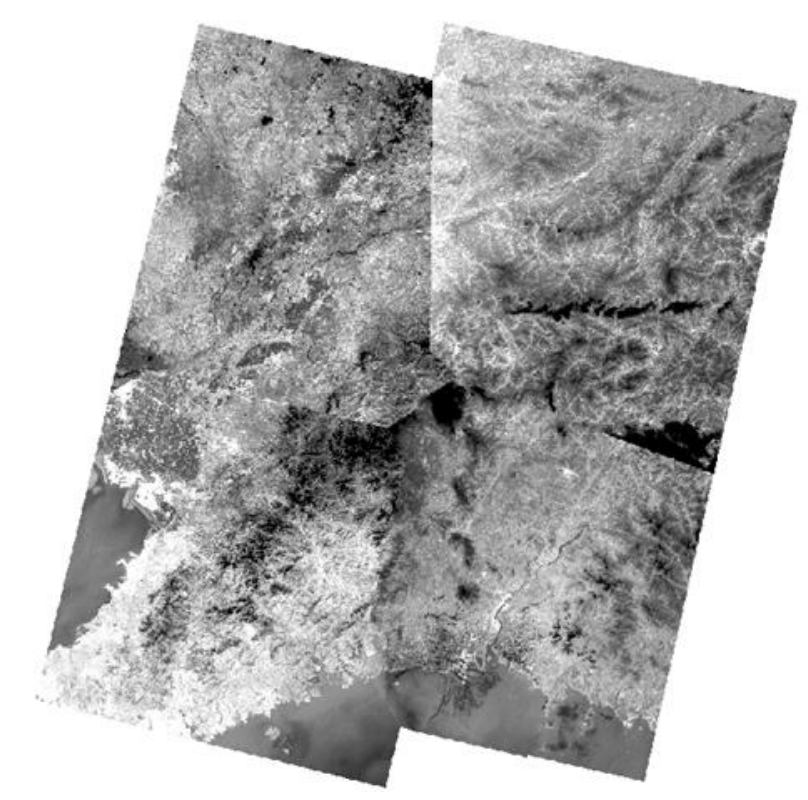

Figure 6. Mosaic image without color correction, seam lines, or feathering.

Obvious contact lines appear at the joints between the images, which are caused by the absences of color correction and seam lines. However, it should be noted that the Landsat 8 satellite revisits an area every 16 days, and sometimes the data from two images taken at very close imaging times may be unusable due to too much cloud cover ( $>50 \%$ ). In this case, only images with a relatively long time difference can be used for mosaicking, which leads to obvious contact lines between the images, and discontinuities in the data at these boundaries, but these differences do not seriously affect the final results.

As the research area is only a small region of this image, the images are cropped according to the range of the selected research area. We cropped the images according to latitude and longitude.

\section{Results}

\subsection{Mapping surface temperature retrieval results}

Based on the Landsat 8 thermal-infrared remote sensing data from each month in 2014, the surface temperature at each point in the study area was extracted using the ENVI software after scaling, band calculation, inlaying, and cutting; then using density slicing and dividing the temperature range. The resulting images of LST maps are shown in Figure 7-14. The pink circles in the figures are the positions of the known hot spring coordinates.

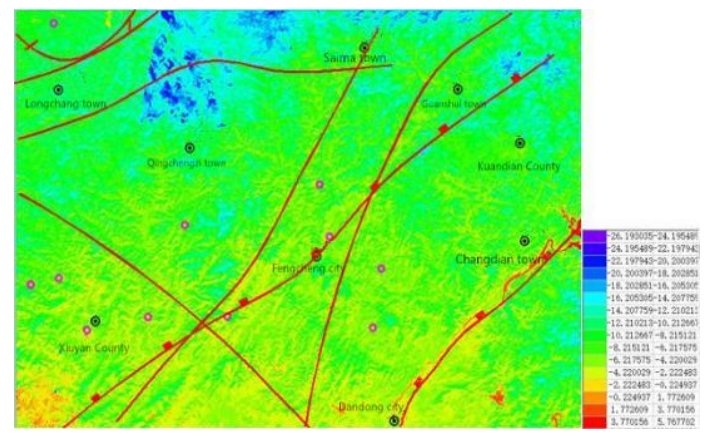


Figure 7. Map of surface temperature retrieval results on Dec. 6, 2014.

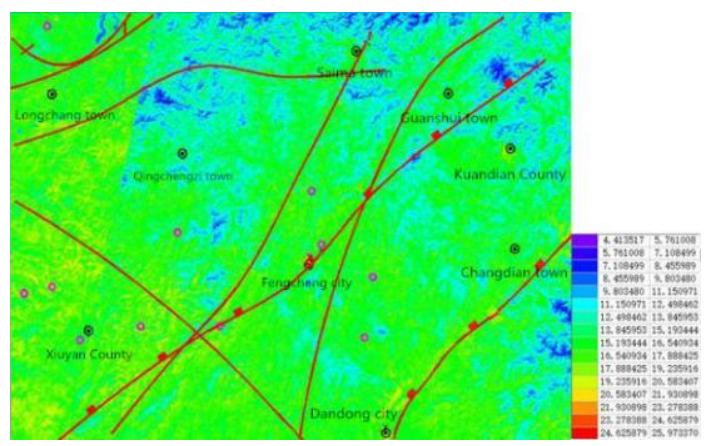

Figure 8. Map of surface temperature retrieval results on Oct. 3, 2014.

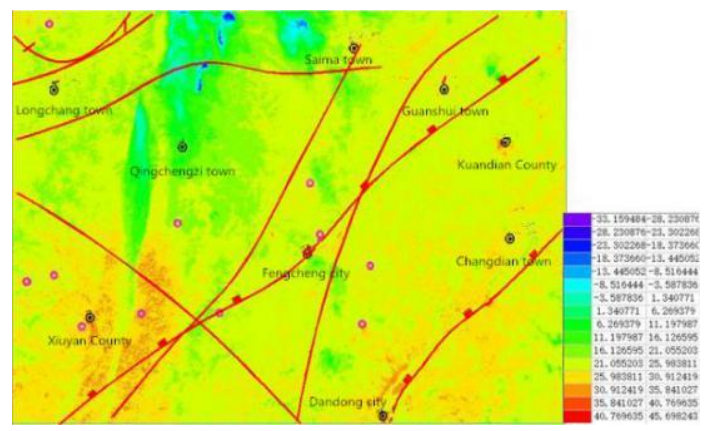

Figure 9. Map of surface temperature retrieval results on Sept. 1, 2014

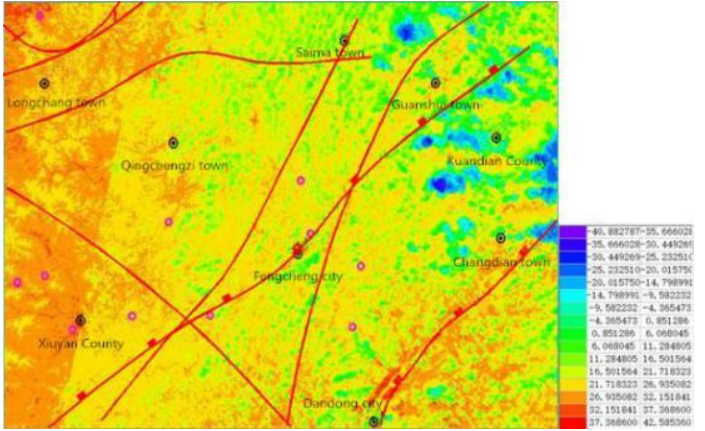

Figure 10. Map of surface temperature retrieval results on Aug. 16, 2014.

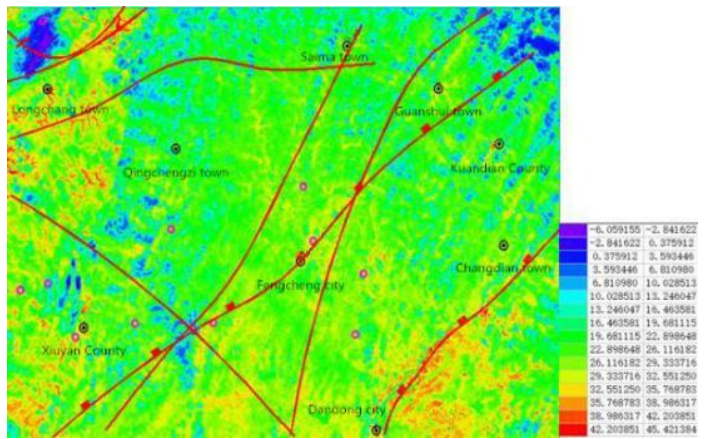

Figure 11. Map of surface temperature retrieval results on Jul. 13, 2014. 


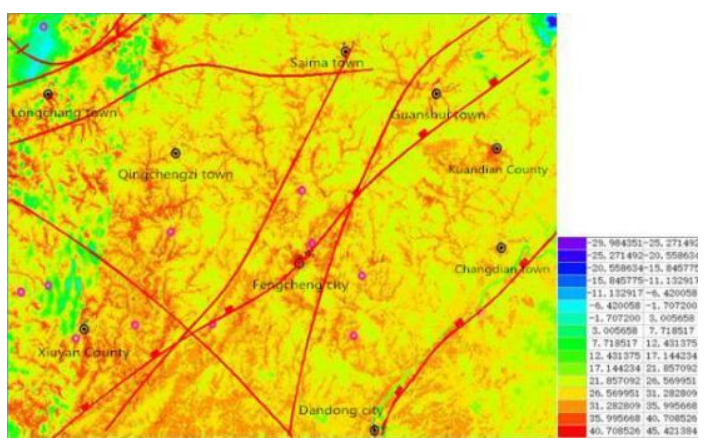

Figure 12. Map of surface temperature retrieval results on May. 28, 2014.

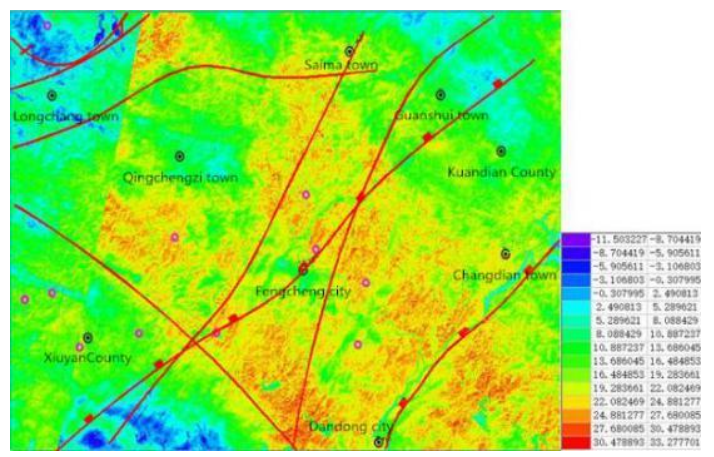

Figure 13. Map of surface temperature retrieval results on Apr. 10, 2014.

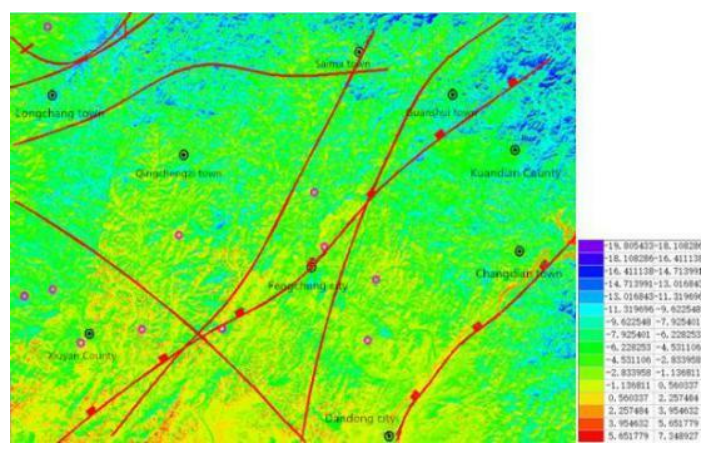

Figure 14. Map of surface temperature retrieval results on Jan. 4, 2014.

Since the remote sensing images were stitched together and are not generated from single data capture, there will be some deviation on the west side of the inversion results, but the overall inversion results will not be affected. The results in Figure 7-14 show that the inversion effect is good enough to identify abnormal-temperature regions, and the results from December, October, June, and January are the best. The hot spring points indicated by the circles and the fault zones are mostly indicated as having abnormal temperatures. Several images show that the lithospheric fault zone of the Yalu River is very abnormal in temperature.

\subsection{Verification of LST retrieval results}

To verify the accuracy of an retrieval algorithm, it is usually necessary to compare the results against values measured on the ground or other standard values. However, due to the difficulty in obtaining these measurements retrospectively and over a large area, the historical 
temperature record of cities and counties provided by the Liaoning meteorological bureau could be used. However, the historical temperature data at the county-level are difficult to obtain and have low credibility. Hence, this paper only used city-level data for analysis. In addition, MODIS LST data were used for verification [21].

Since the spatial resolution of Landsat 8 is 30 meters (the real resolution of the sensor is 100 meters) and the spatial resolution of MOD11_L2 is $1 \mathrm{~km}$, the Landsat 8 temperature retrieval results need to be translated to the same resolution for comparison [22]. Therefore, Landsat 8 needs to be resampled to $1 \mathrm{~km}$ resolution to match it to the MOD11_L2 data [23].

Table 1 lists the results of resampled Landsat 8 city-level points retrieval in each month of 2014 and the corresponding MOD11_L2 data. Meanwhile, the Fengcheng area in the Landsat 8 and MODIS surface temperature products research area was cut out using the administrative boundary file of Liaoning province through ArcGIS 10.1 software. Then, the highest and lowest temperatures in the meteorological data were compared and evaluated with the data of the maximum, minimum, and average values of the historical months in the Fengcheng image results. The results are listed in Table 2:

Table 1. Landsat 8 and MOD11 point location temperature comparison.

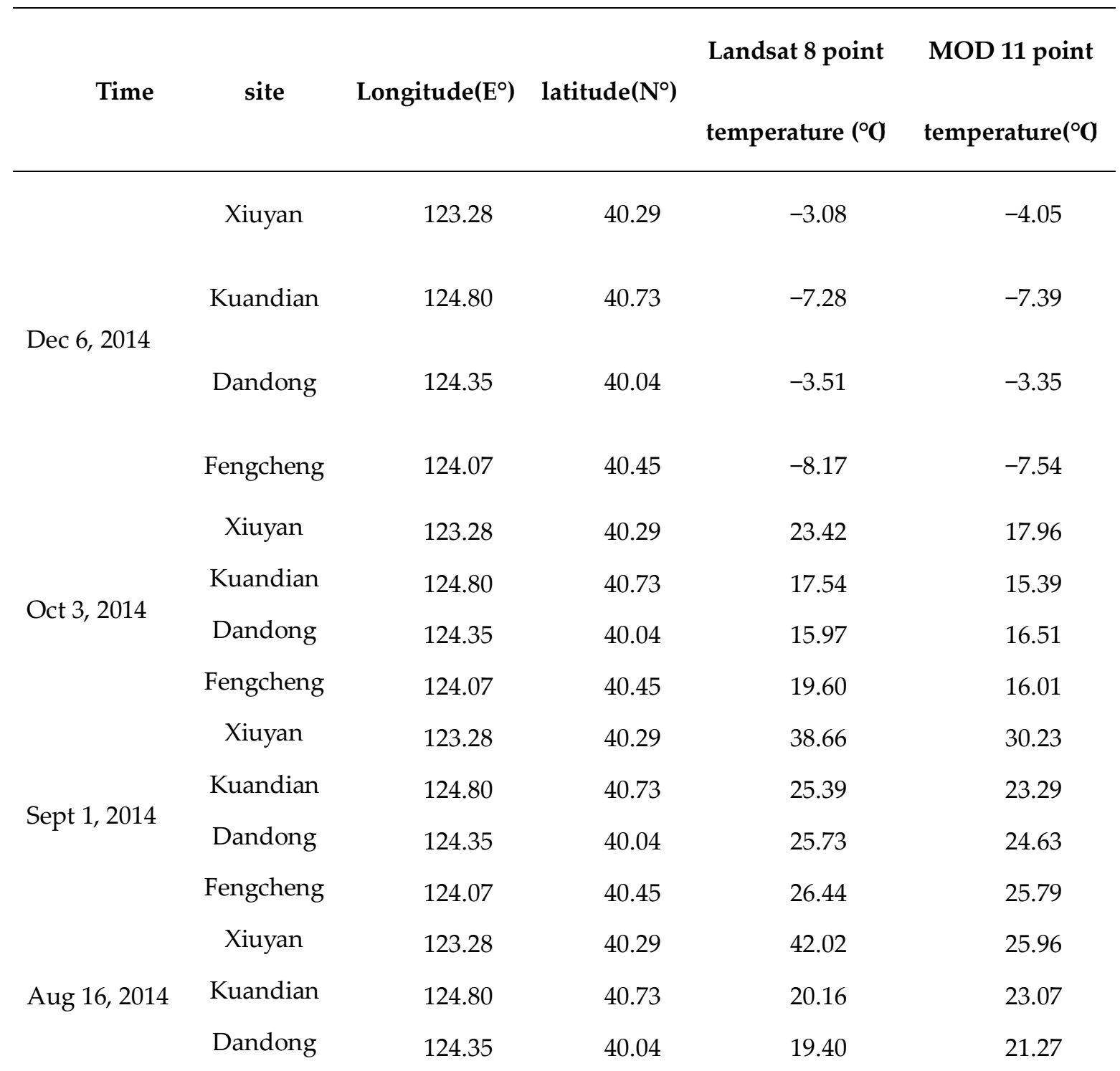




\begin{tabular}{cccccc} 
& Fengcheng & 124.07 & 40.45 & 31.16 & 25.23 \\
& Xiuyan & 123.28 & 40.29 & 36.81 & 32.95 \\
Jul 13, 2014 & Kuandian & 124.80 & 40.73 & 26.08 & 27.52 \\
& Dandong & 124.35 & 40.04 & 24.61 & 25.27 \\
& Fengcheng & 124.07 & 40.45 & 36.65 & 27.90 \\
& Xiuyan & 123.28 & 40.29 & 36.81 & 33.35 \\
May 28, 2014 & Kuandian & 124.80 & 40.73 & 27.13 & 23.08 \\
& Dandong & 124.35 & 40.04 & 27.09 & 27.93 \\
& Fengcheng & 124.07 & 40.45 & 39.02 & 26.07 \\
& Xiuyan & 123.28 & 40.29 & 19.83 & 22.35 \\
Apr 10, 2014 & Kuandian & 124.80 & 40.73 & 13.99 & 10.07 \\
& Dandong & 124.35 & 40.04 & 15.57 & 15.85 \\
& Fengcheng & 124.07 & 40.45 & 15.18 & 18.51 \\
& Xiuyan & 123.28 & 40.29 & -1.09 & -3.08 \\
& Kuandian & 124.80 & 40.73 & -4.87 & -4.64 \\
Jan 4, 2014 & Dandong & 124.35 & 40.04 & -0.19 & 0.79 \\
& Fengcheng & 124.07 & 40.45 & -5.38 & -4.92 \\
\hline & & & &
\end{tabular}

The area of Fengcheng after resampling the Landsat 8 results is shown in Figure. 17:

63

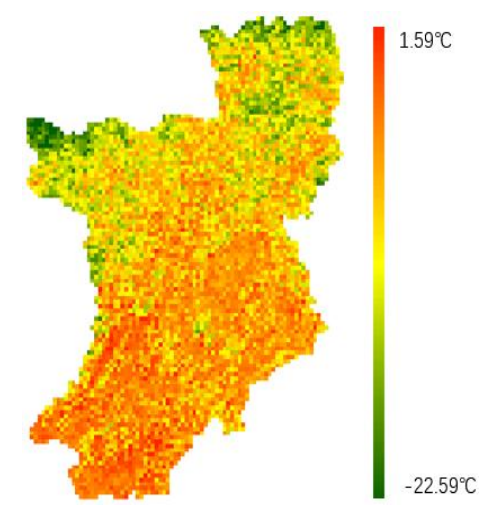

64 resulting image on Dec. 6, 2014.

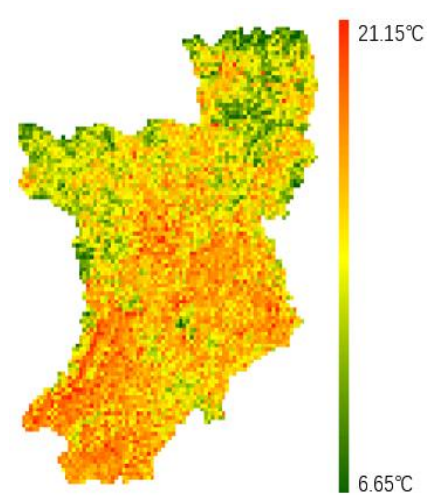

resulting image on Oct. 3, 2014. 
65

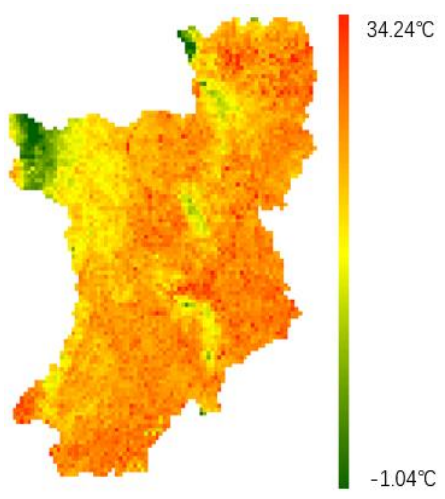

66 resulting image on Sept. 1,2014.

67

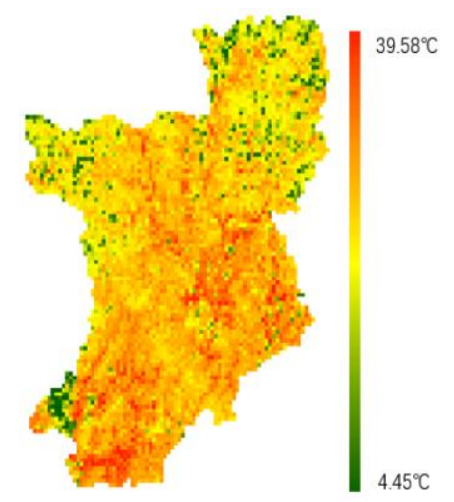

68

resulting image on Jun. 13, 2014.

69

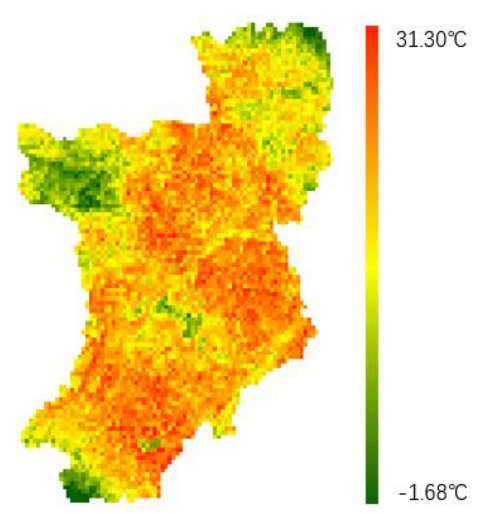

resulting image on Apr. 10, 2014.

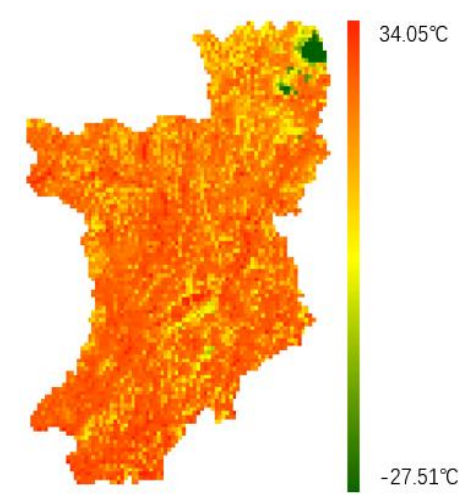

resulting image on Aug. 16, 2014.

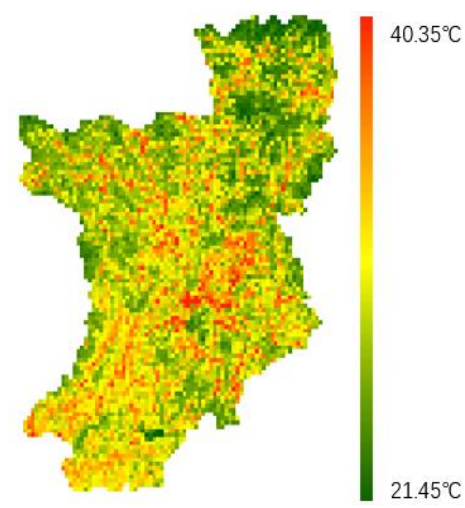

resulting image on May. 28, 2014.

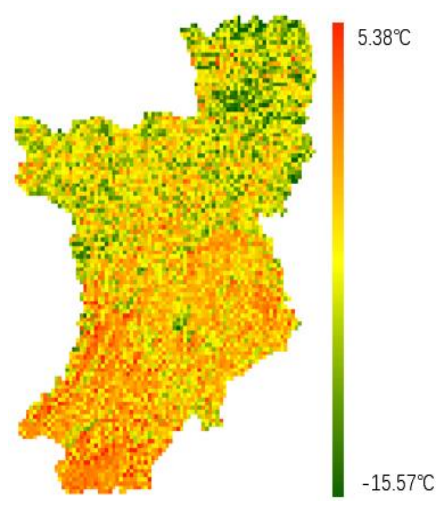

resulting image on Jan. 4, 2014.

71

Figure 15. Land surface temperature retrieval results of Fengcheng City in each month of 2014.

MODIS LST data around Fengcheng are shown in Figure. 16: 
74

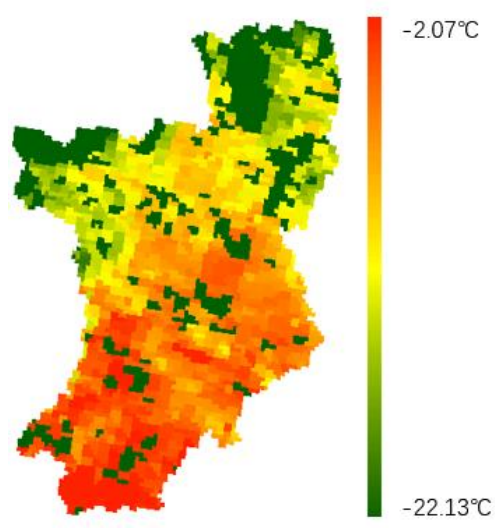

75

resulting image on Dec. 6, 2014.

76

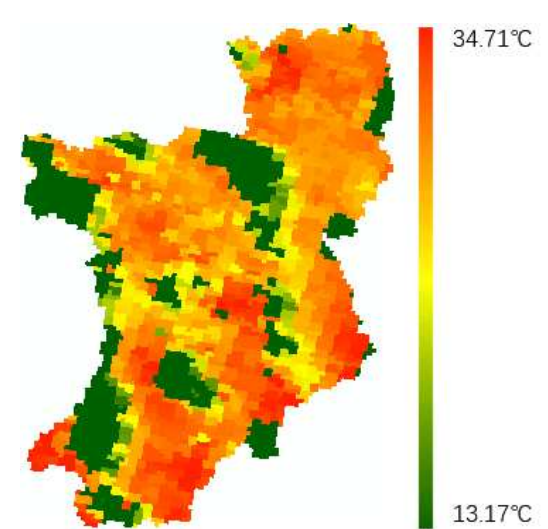

resulting image on Sept.1,2014.

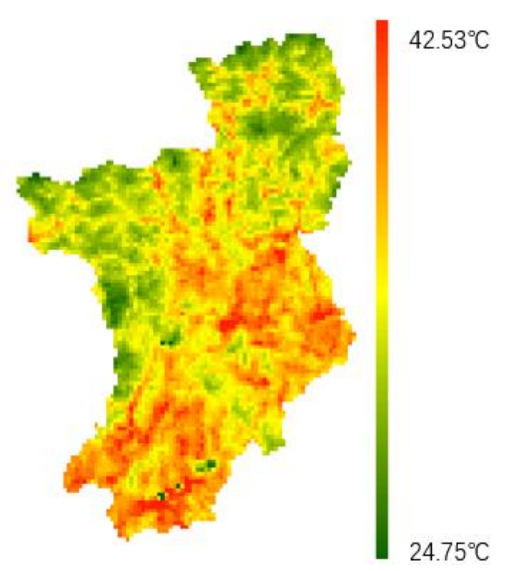

resulting image on Jun. 13, 2014.

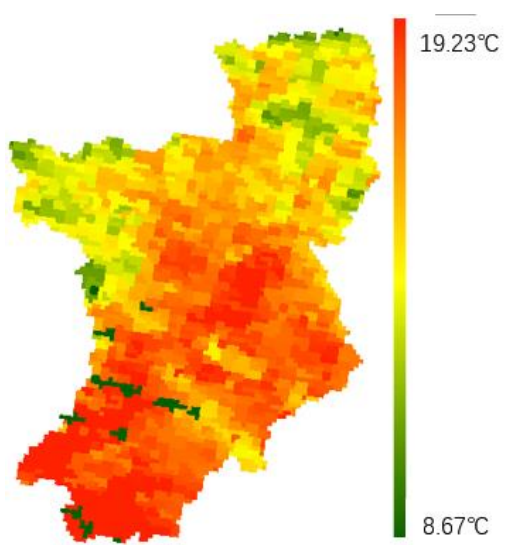

resulting image on Oct. 3,2014.

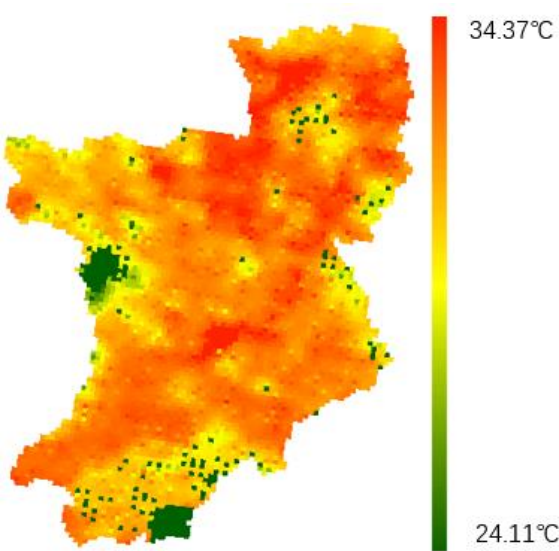

resulting image on Aug. 16, 2014.

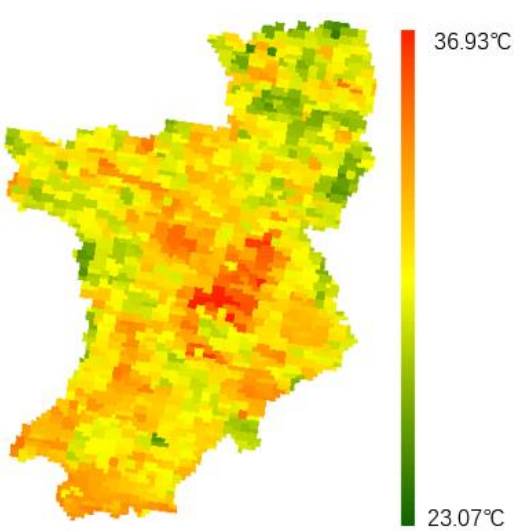

resulting image on May. 28, 2014. 


\begin{tabular}{|c|c|c|c|c|c|c|c|c|}
\hline 80 & & & $15.45^{\circ} \mathrm{C}$ & & & 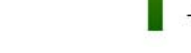 & $87^{\circ} \mathrm{C}$ & \\
\hline 81 & \multicolumn{4}{|c|}{ resulting image on Apr. 10, 2014} & \multicolumn{4}{|c|}{ resulting image on Jan. 4, 2014} \\
\hline 82 & \multirow{2}{*}{\multicolumn{8}{|c|}{$\begin{array}{l}\text { Figure 16. Processing of the MODIS LST data of Fengcheng City in each month of } \\
2014 .\end{array}$}} \\
\hline 83 & & & & & & & & \\
\hline 84 & \multicolumn{8}{|c|}{ Table 2. Maximum and average values from the two datasets compared with meteorological } \\
\hline 85 & & & & & & & & \\
\hline & Highest & Lowest & L8 & L8 & L8 & MOD11 & MOD11 & MOD11 \\
\hline Time & temperature & temperature & maximum & minimum & average & $\begin{array}{l}\text { maximum } \\
\text { value }\left({ }^{\circ} \mathrm{O}\right.\end{array}$ & $\begin{array}{l}\text { minimum } \\
\text { value }\left({ }^{\circ} \mathrm{O}\right.\end{array}$ & $\begin{array}{l}\text { average } \\
\left.\text { value }{ }^{\circ} \mathrm{O}\right)\end{array}$ \\
\hline & $\left({ }^{\circ} \mathrm{O}\right.$ & $\left({ }^{\circ} \mathrm{O}\right.$ & value $\left({ }^{\circ} \mathrm{O}\right.$ & value $\left({ }^{\circ} \mathrm{O}\right.$ & value $\left({ }^{\circ} \mathrm{O}\right.$ & & & \\
\hline 2014 & -4 & -15 & 1.59 & -22.59 & -7.46 & -2.07 & -22.13 & -6.02 \\
\hline 014 & 19 & 3 & 21.15 & 6.65 & 15.08 & 19.23 & 8.67 & 16.23 \\
\hline 2014 & 28 & 18 & 34.24 & -1.04 & 23.38 & 34.71 & 13.17 & 23.20 \\
\hline 2014 & 27 & 18 & 34.05 & -27.51 & 22.91 & 34.37 & 24.11 & 25.07 \\
\hline 2014 & 30 & 15 & 39.58 & 4.45 & 24.68 & 42.35 & 24.75 & 27.5 \\
\hline 2014 & 30 & 14 & 40.35 & 21.45 & 29.24 & 36.93 & 23.07 & 27.93 \\
\hline 2014 & 19 & 4 & 31.30 & -1.68 & 19.13 & 31.63 & 15.45 & 21.20 \\
\hline 014 & -1 & -11 & 5.38 & -15.57 & -3.82 & 3.35 & -9.87 & -2.03 \\
\hline
\end{tabular}

86 The data in Table 2 shows that Landsat 8 point positions temperature and the 87 temperature of from the MODIS geothermal dataset were similar, most within $\pm 2^{\circ} \mathrm{C}$ of each 88 other, some within $\pm 3^{\circ} \mathrm{C}$, and only a few points had a serious difference in temperature. The 89 point of great difference is likely caused by different initial resolutions or the urban 90 heat-island effect and appears in Figure 15, Figure 16, and Table 1. The maximum 91 temperature, the lowest temperature, and the average temperature of the two kinds of data 
basically correspond with each other. Thick clouds in some parts of the original remote sensing images make the temperature lower, and low temperatures are also caused by the water in the study area. Since the original image of the MODIS LST products is somewhat incomplete and partially striped, the data will be filled in by default when opened in the ArcGIS software. For example, the dark green areas in the processing results of MOD11 geothermal products in Figure 18 may have been caused this way. Although these blank stripes do not participate in the classification of results, they affect the maximum and average values. Finally, the statistical histogram features of the images of the two results show that the remote-sensing data is basically consistent with the temperature data from the weather bureau. Most of the pixels are within the range of the urban meteorological data. The above analysis shows that the results of LST retrieval from Landsat 8 data are accurate enough to give direction to geothermal exploration.

\subsection{Discussion}

Observation of the anomalous areas in the landsat8 image revealed that the high-temperature areas are very close to the actual hot spring spots and the location of the fault zone. Comparing the Landsat 8 position temperatures with the MODIS LST data, we see that the inferred surface temperatures were quite accurate. The abnormal zones in the inferred results match well with the local hot spring sites, structures, and historical local air temperatures. The results show that the inferred results are highly precise, and correlate well with the known distribution of local geothermal resources. These results show that publically available thermal-infrared remote sensing data can be applied for geothermal exploration.

\section{Conclusions}

In this paper, based on the thermal-infrared remote sensing data from Landsat 8, the LST of the Dandong-Liaoyang geothermal area in 2014 was inferred using the atmospheric-correction method. The results were compared with the known spatial distribution of local hot spring sites and the verified data from the MODIS LST dataset. We draw three main conclusions from the results.

(1) Compared with previous Landsat satellites, Landsat 8's sensor band is optimized while ensuring data continuity and its spatial resolution is up to 30 meters, which makes it better suited for the retrieval of surface temperatures.

(2) Geothermal information was extracted by the atmospheric-correction or thermal-channel method. The inversion results in this study are high-quality, and the geothermal anomalies within the study area were extracted effectively. Comprehensive verification of the inversion results against the known hot spring coordinates; LST from MOD11_L2, and local historical air temperature values in the geothermal area was successful. The Landsat 8 data turned out to be most useful in January and September.

(3) Surface temperature inferred from thermal-infrared remote sensing data can accurately yield the desired information about the study area. When combined with various verification methods, the inversion results are very accurate. The images obtained by thermal-infrared remote sensing inversion are characterized by high accuracy, simple and fast 
data-source acquisition, good economy, and fast data analysis. The spatial and temperature resolution can meet the requirements for geothermal exploration, so the data should prove effective for monitoring subtle temperature changes on the earth's surface.

Though the thermal-infrared remote sensing data offered highly accurate information about surface temperature anomalies, two main shortcomings remain to be addressed.

When the geothermal anomaly information is extracted from the infrared temperature data, only temperature anomalies in the surface or at shallow depths can be obtained. Space-based sensors cannot offer any insight about geothermal temperatures deeper under the surface, which are also useful for the exploration of geothermal resources.

There are still certain errors in surface temperature inference. These errors come from atmospheric disturbances, the surface material structure, and the quality and acquisition time of remote sensing data, along with seasonal errors due to the serious vegetation cover in summer and snow cover in winter.

\section{Author Contributions:}

Writing the original draft, Jinxin He; Writing-review and editing, Yiming Luan; Supervision and made improvements to the manuscript, Wenqing Li; Collecting data and data processing, Ning Ma; Data processing, Huanzhao Sun.

\section{Acknowledgements}

This work was supported by Geological Investigation Projects in China (Grant No. 1212011220247) and Jilin Provincial Excellent Young Talents Funding (20180520089JH). We also thank the anonymous reviewers for their helpful suggestions.

\section{References}

1. He, J.; Sun, H.; Li, W.; Zheng, B.; \& Jiang,T. Land Surface Temperature Retrieval in Eastern Liaoning Geothermal Area Based on Thermal Infrared Remote Sensing Data. J. JLU. (Infor Sci Edi). 2018, 36, 62-68.

2. He, J.; Zheng, B.; Li, W.; Yang, L.; \& Sun, H. Land Surface Temperature Retrieval of the Geothermal Area in Eastern Liaoning, China, Based on Thermal Infrared Remotely Sensed Data of MODIS. J. Indian. Soc. Remote. 2018, 46, 1023-1034. https://doi.org/10.1007/s12524-018-0765-3.

3. Qin, Z.;Gao, M.; Qin, X.; Li W.;\& Xu.B. Methodology to retrieve land surface temperature from MODIS data for agricultural drought monitoring in China. J. Nat-Disa. 2005, 14, 64-71.

4. Jiménez-Muñoz, J. C. \& Sobrino, J. A. A generalized single-channel method for retrieving land surface temperature from remote sensing data. J. Geophys. Res-atmos. 2003, 108. https://doi.org/10.1029/2003JD003480.

5. Qin, Z.; Dall'Olmo, G.; Karnieli, A.; \& Berliner, P. Derivation of split window algorithm and its sensitivity analysis for retrieving land surface temperature from NOAA-advanced very high resolution radiometer data. J. Geophys. Res-atmos. 2001a, 106, 22655-22670. https://doi.org/10.1029/2000JD900452.

6. Qin, Z.; Karnieli, A.; \& Berliner, P. A mono-window algorithm for retrieving land surface temperature from Landsat TM data and its application to the Israel-Egypt border region. Int. J. Remote Sens. 2001b, 22, 3719-3746. https://doi.org/10.1080/01431160010006971. 
7. Sobrino, J. A.; Li, Z. L.; Stoll, M. P.; \& Becker, F. Multi-channel and multi-angle algorithms for estimating sea and land surface temperature with ATSR data. Int. J. Remote Sens. 1996, 17, 2089-2114. https://doi.org/10.1080/01431169608948760.

8. Gillespie, A.; Rokugawa, S.; Matsunaga, T.; Cothern, J. S.; Hook, S.; \& Kahle, A. B. A temperature and emissivity separation algorithm for Advanced Spaceborne Thermal Emission and Reflection Radiometer (ASTER) images. IEEE. T. Geosci. Remote. 1998, 36, 1113-1126. http://dx.doi.org/10.1109/36.700995.

9. Li, F.; Jackson, T. J.; Kustas, W. P.; Schmugge, T. J.; French, A. N.; Cosh, M. H.; \& Bindlish, R. Deriving land surface temperature from Landsat 5 and 7 during SMEX02/SMACEX. Remote Sens. Environ. 2004, 92, 521-534. https://doi.org/10.1016/j.rse.2004.02.018.

10. Sobrino, J. A.; Jimenez-Munoz, J. C.; \& Paolini, L. Land surface temperature retrieval from LANDSAT TM 5. Remote Sens. Environ. 2004, 90, 434-440. http://dx.doi.org/10.1016/j.rse.2004.02.003.

11. Wang, J. The Metallogenic Regularity Discussed and Prospecting Target Area Prognosis of Intermediate-acid Rock in Liaodong Area. Master's Degree, Chengdu University of Technology, Chengdu, 2011.

12. Zhang, G. Polymetallic Ore Research on Metallogenic Regularity and Metallogenic Prediction of Fengcheng Jiguanshan Area in Liaoning Province. Master's Degree, Liaoning Technical University, Jinzhou, 2015.

13. Li, W. Geothermal characteristics of eastern Liaoning and effects of rock radiative heat generation on geothermal resource potential. Master's Degree, Jilin University, Changchun, 2015.

14. Rozenstein, O., Qin, Z., Derimian, Y., \& Karnieli, A. Derivation of land surface temperature for Landsat-8 TIRS using a split window algorithm. Sensors. 2014, 14, 5768-5780. http://dx.doi.org/10.3390/s140405768.

15. Zhang, Y. Introduction to Landsat 8. Remote Sens. Land. Reso. 2013, 25, 176-177.

16. $\mathrm{Xu}, \mathrm{H}$. Retrieval of the reflectance and land surface temperature of the newly-launched Landsat 8 satellite. Chinese. J. Geophy. 2015, 58, 741-747. http://dx.doi.org/10.6038/cij20150304.

17. Liu, G.\& Wang, J. Research on Urban Heat Island Effect Based on Landsat TM Images of Tangshan City. Envron. Sci. Sur. 2015, 34, 118-122. https://doi.org/10.3969/j.issn.1673-9655.2015.04.026.

18. De Klerk, H. M.; Gilbertson, J.; Lück-Vogel, M.; Kemp, J.; \& Munch, Z. Using remote sensing in support of environmental management: A framework for selecting products, algorithms and methods. J. Environ Manage. 2016, 182, 564-573. https://doi.org/10.1016/j.jenvman.2016.07.073.

19. $\mathrm{Xu}, \mathrm{H}$. Change of Landsat 8 TIRS calibration parameters and its effect on land surface temperature retrieval. J. Remote Sens. 2016, 20, 229-235. http://dx.doi.org/10.11834/jrs.20165165.

20. Yu, X.; Guo, X.; \& Wu, Z. Land surface temperature retrieval from Landsat 8 TIRS-Comparison between radiative transfer equation-based method, split window algorithm and single channel method. Remote Sens. 2014, 6, 9829-9852. http://dx.doi.org/10.3390/rs6109829.

21. Wan, Z. \& Li, Z. L. A physics-based algorithm for retrieving land-surface emissivity and temperature from EOS/MODIS data. IEET $T$ Geosci Remote. 1997, 35, 980-996. https://doi.org/10.1109/36.602541.

22. Song, T.;Duan, Z.; Liu,J.; Shi, J.; Yan, F.; Sheng, S.; \& Wu, W. Comparison of four algorithms to retrieve land surface temperature using Landsat 8 satellite. J. Remote Sens. 2015, 19, 451-464. http://dx.doi.org/10.11834/jrs.20154180. 
23. Wan, Z.; Zhang, Y.; Zhang, Q.; \& Li, Z. L. Quality assessment and validation of the MODIS global surface https://doi.org/10.1080/0143116031000116417. 


\section{Figures}

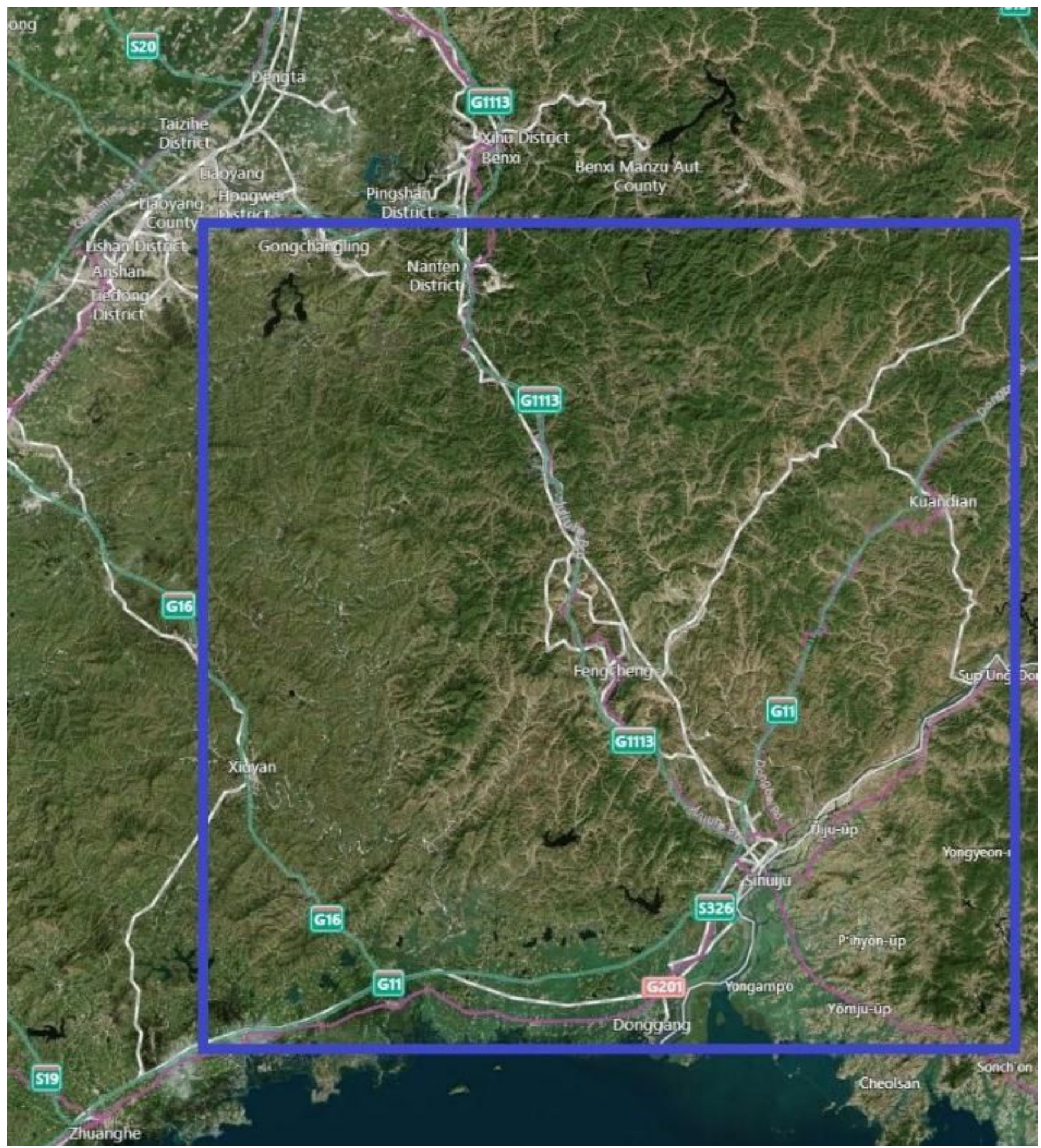

\section{Figure 1}

Location of the study area is shown in blue box. 


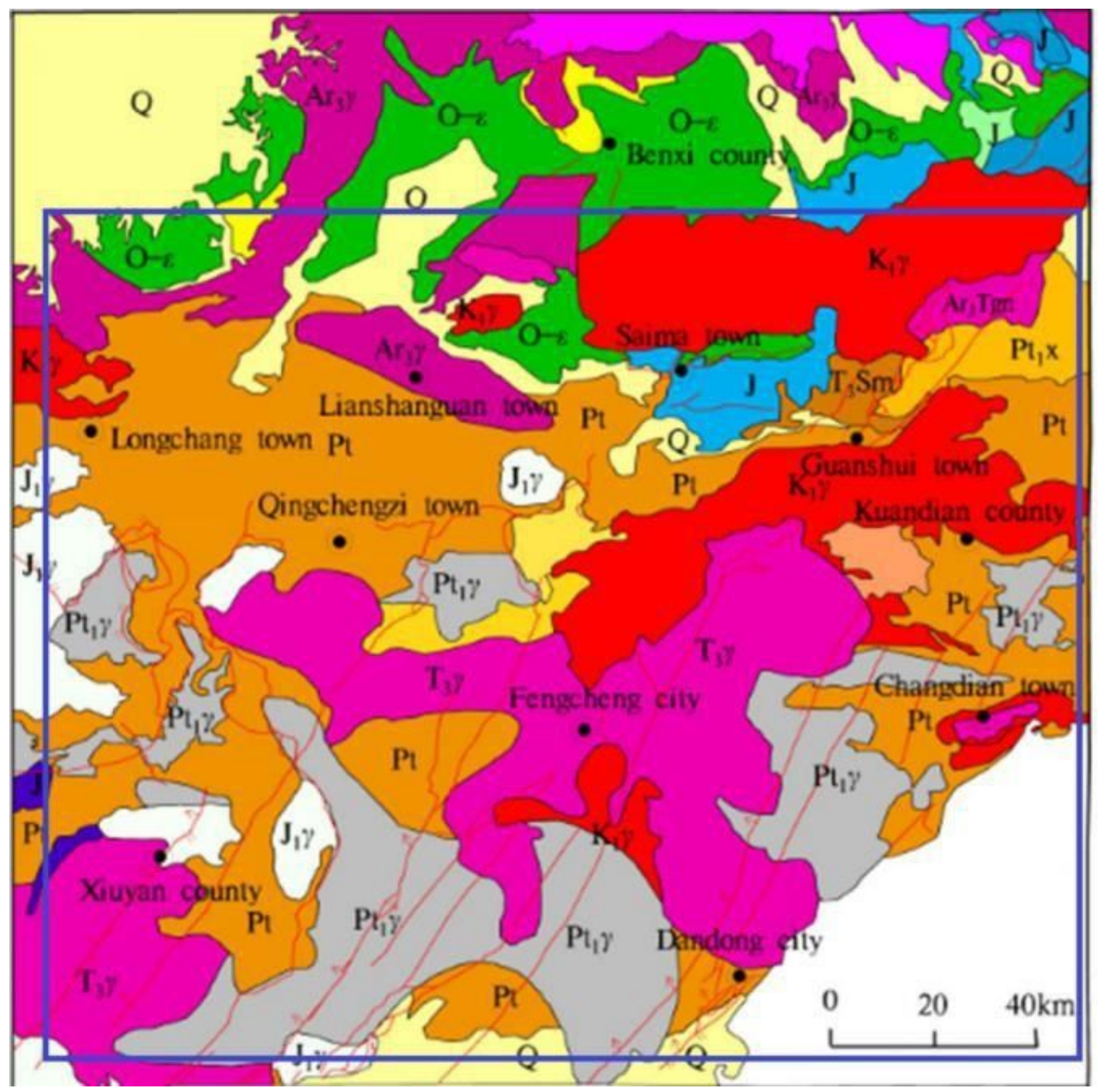

Figure 2

Regional stratigraphy of the study area is shown in blue box. (Reproduced with permission from Li, 2015) 


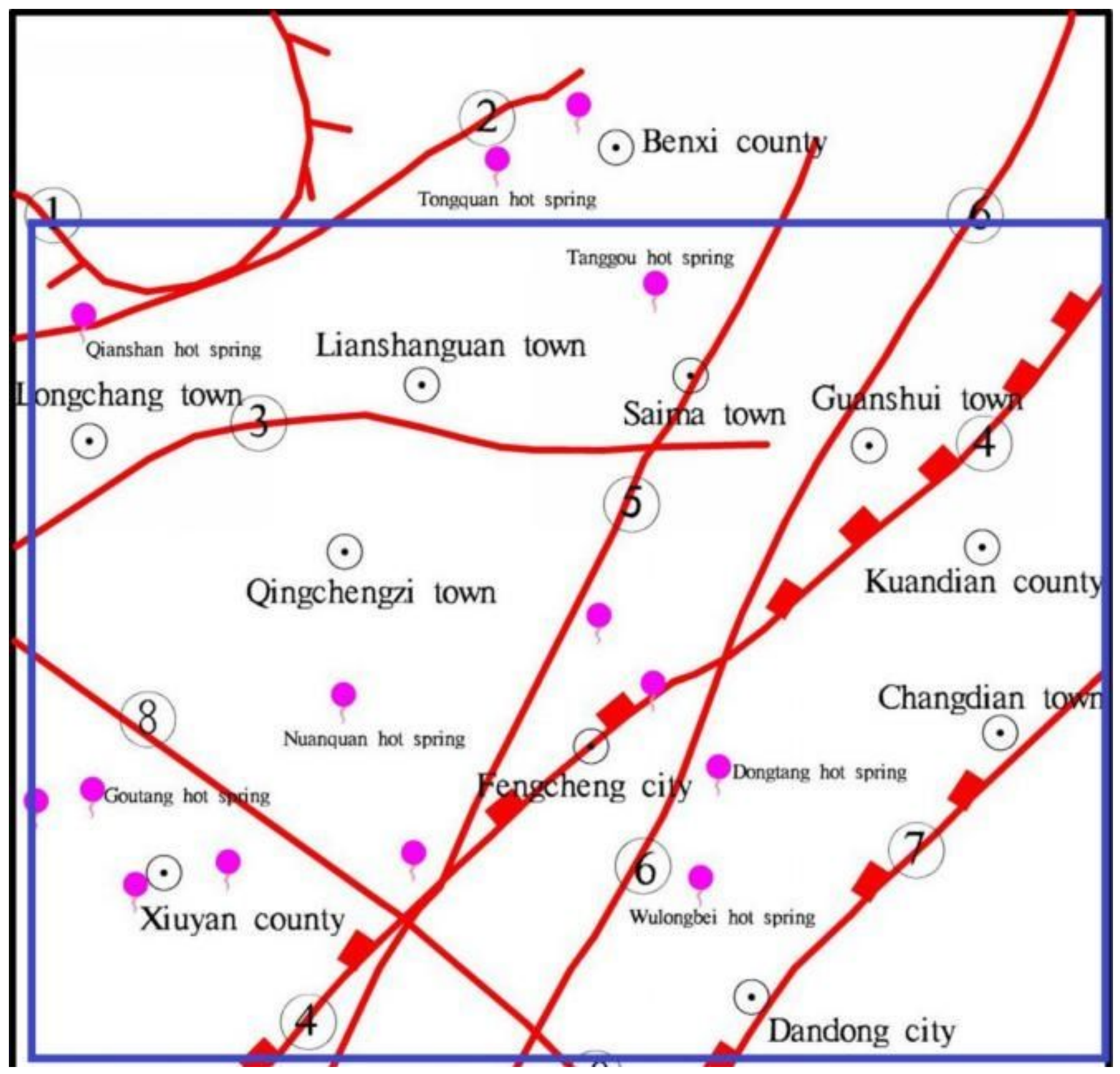

Figure 3

Geothermal characteristics of the study area is shown in blue box. (Reproduced with permission from Li, 2015) 


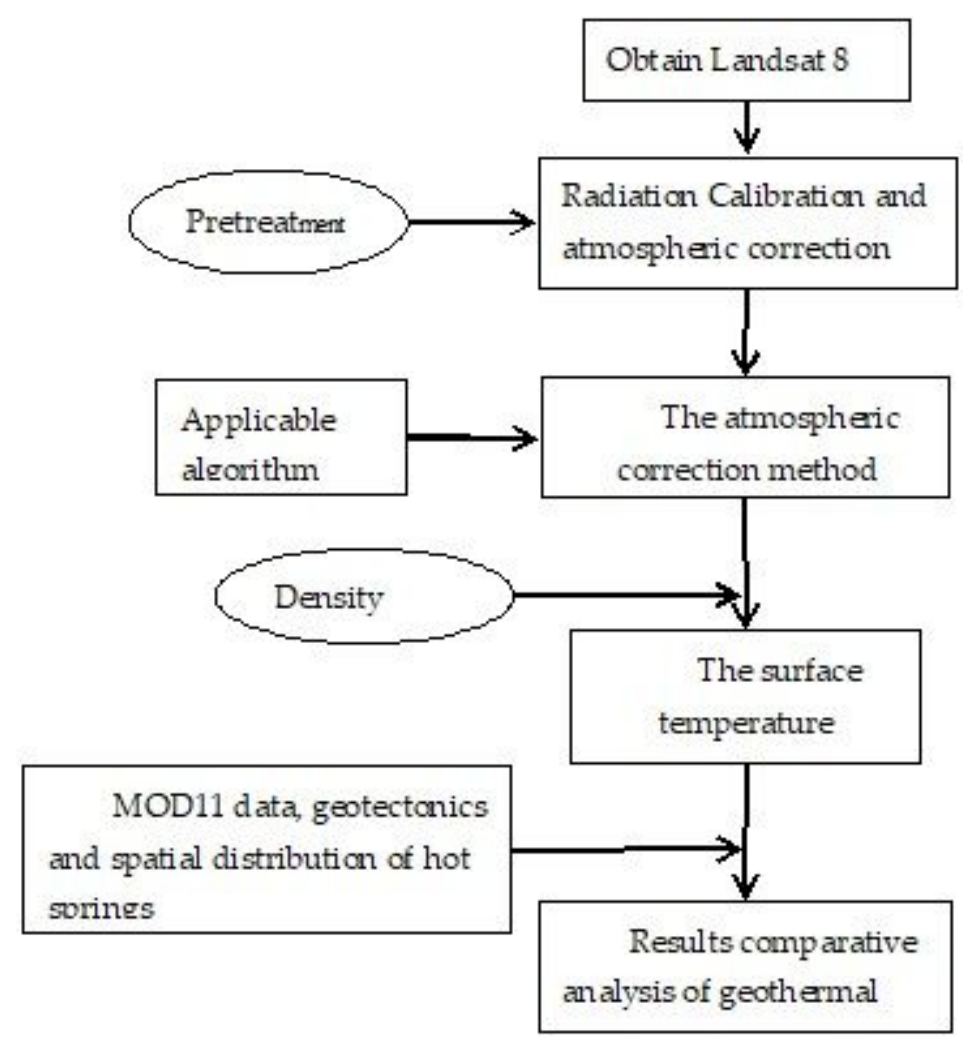

Figure 4

Basic flow chart. 


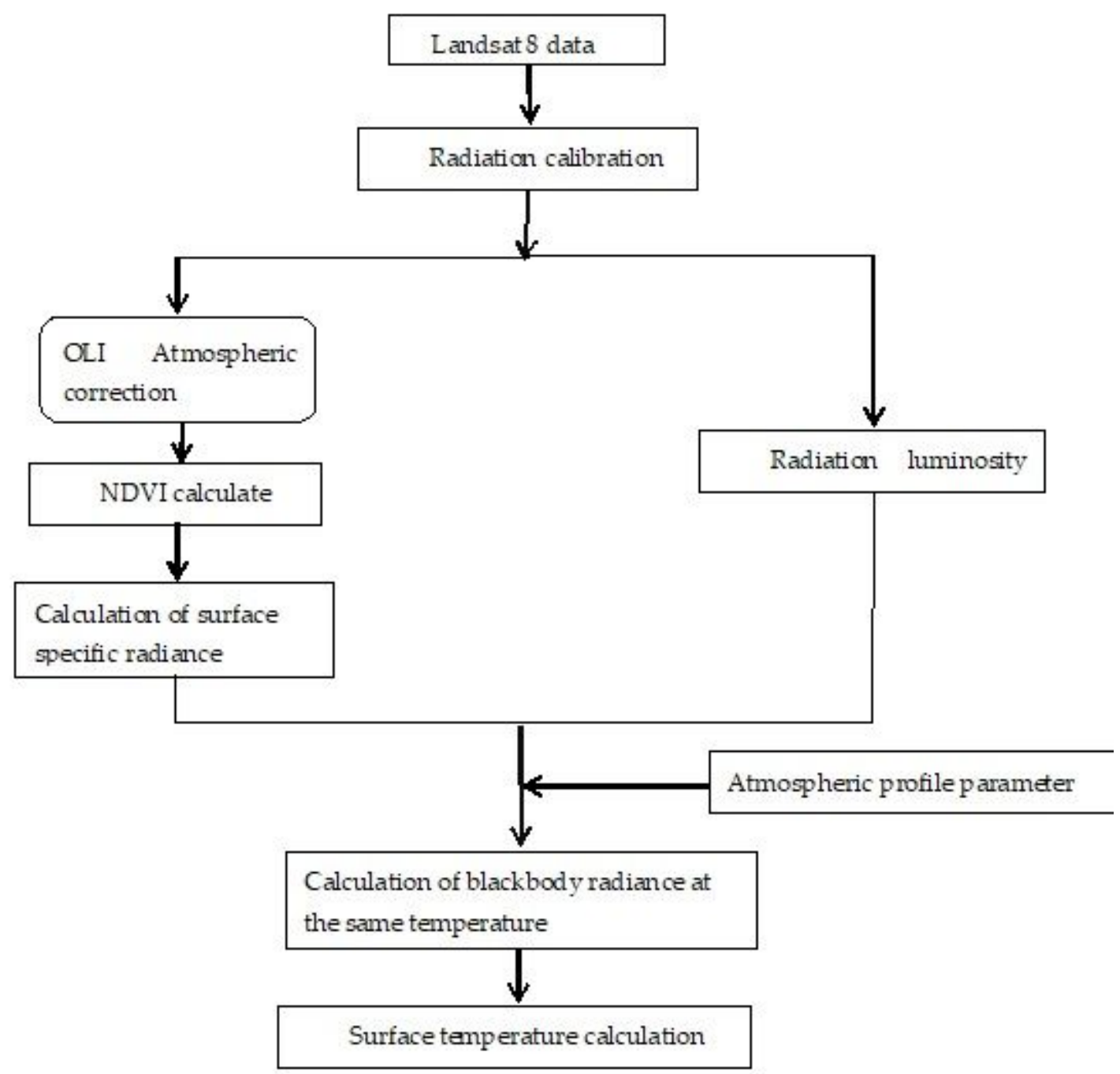

Figure 5

Landsat 8 surface-temperature retrieval flow chart based on atmospheric correction. 


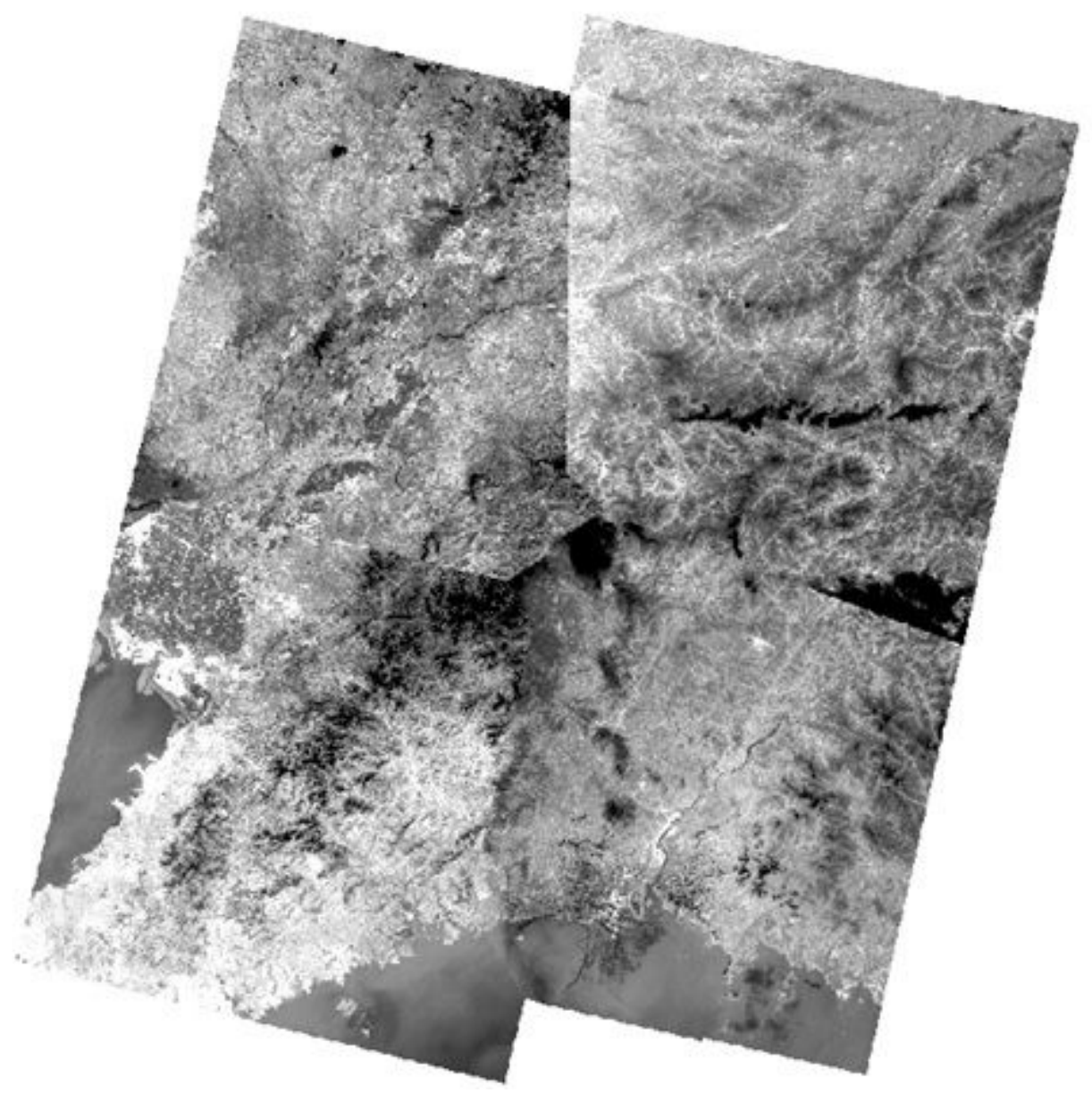

Figure 6

Mosaic image without color correction, seam lines, or feathering.

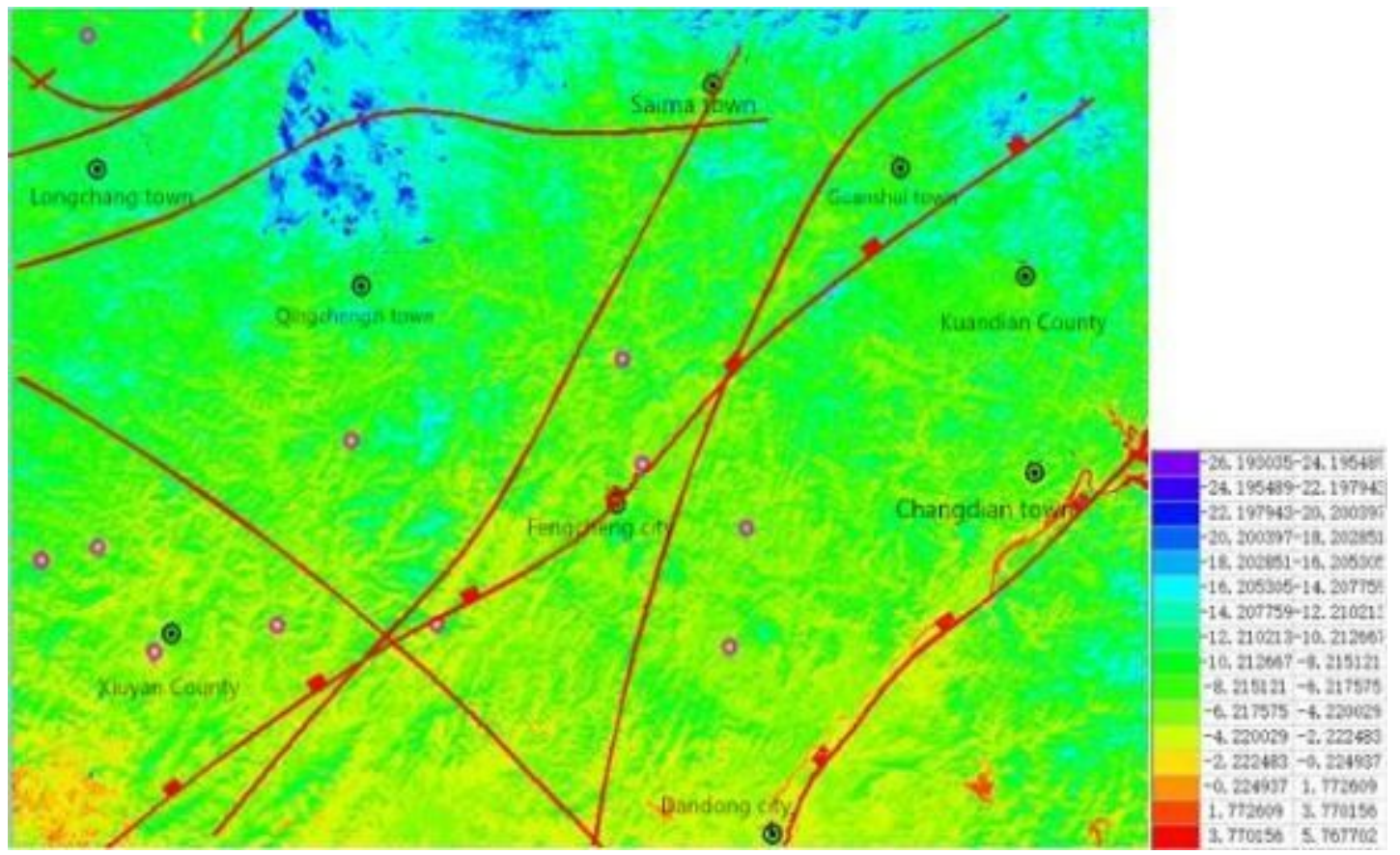

Figure 7 
Map of surface temperature retrieval results on Dec. 6, 2014.

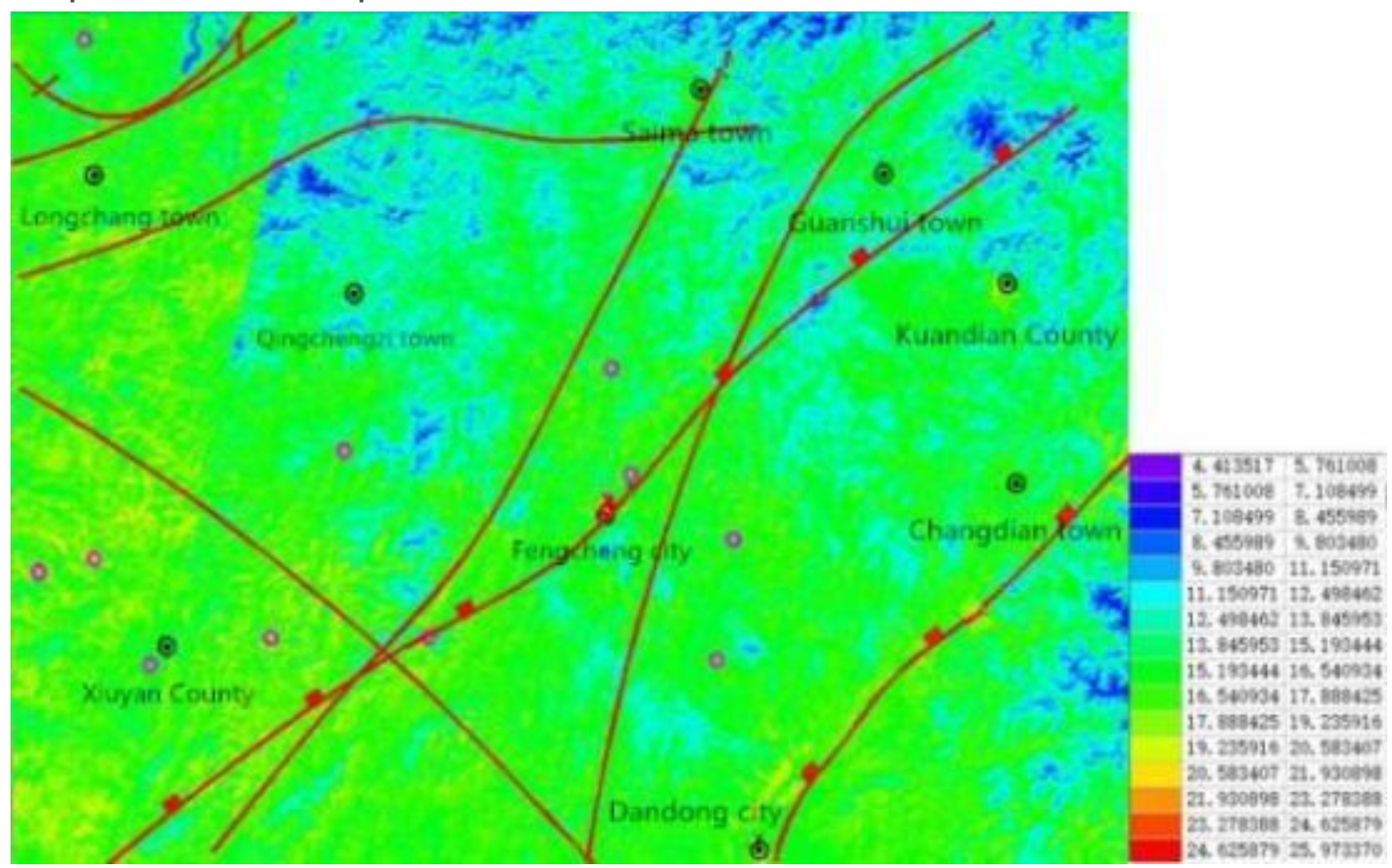

Figure 8

Map of surface temperature retrieval results on Oct. 3, 2014.

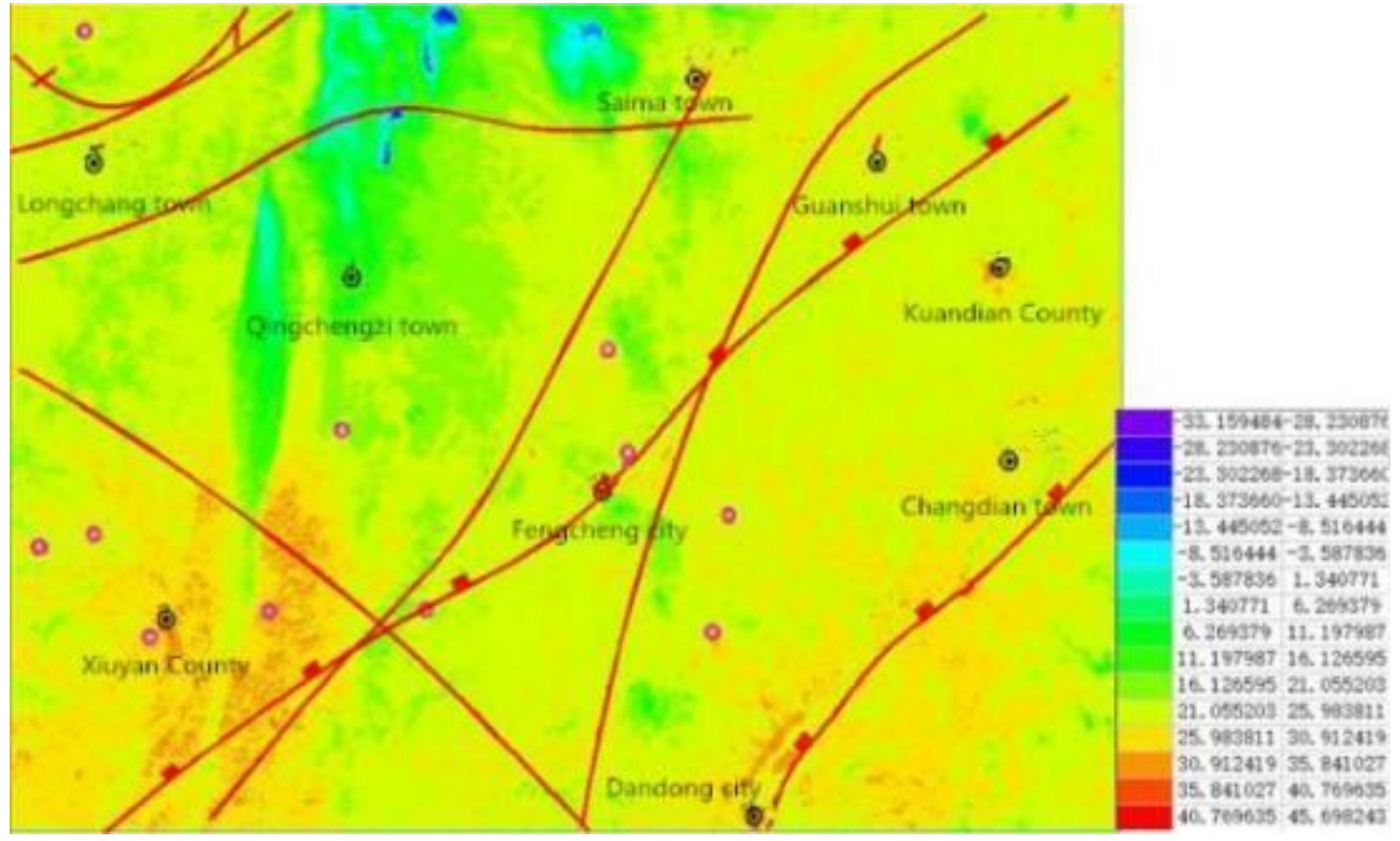

Figure 9

Map of surface temperature retrieval results on Sept. 1, 2014 


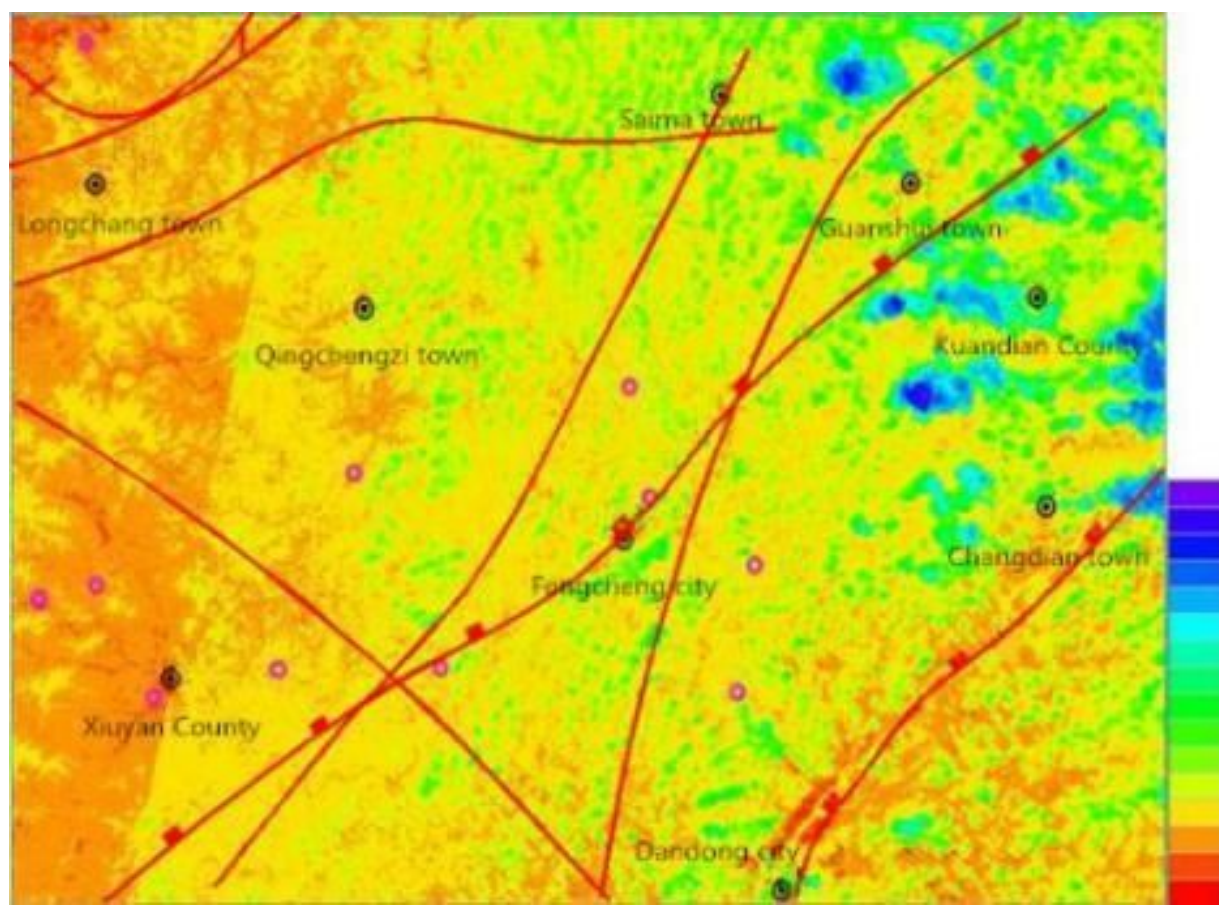

4. 25. $006024-90,44020$ 30. 46205-25. 212510 25. 232510-20, 01575: 20. 045750-14. 7675

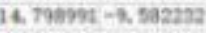
$-2.502232-4.365673$ 4. 305673 Q. 251286

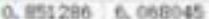
6. Oelapes 11.214605 11. 284005 16. 501504 6., 501564 21. 716321 11. 718123 20. 905002 8. 625002 22. 15164 $32.15184137,396000$ 37, 306000 42. 595280

Figure 10

Map of surface temperature retrieval results on Aug. 16, 2014.

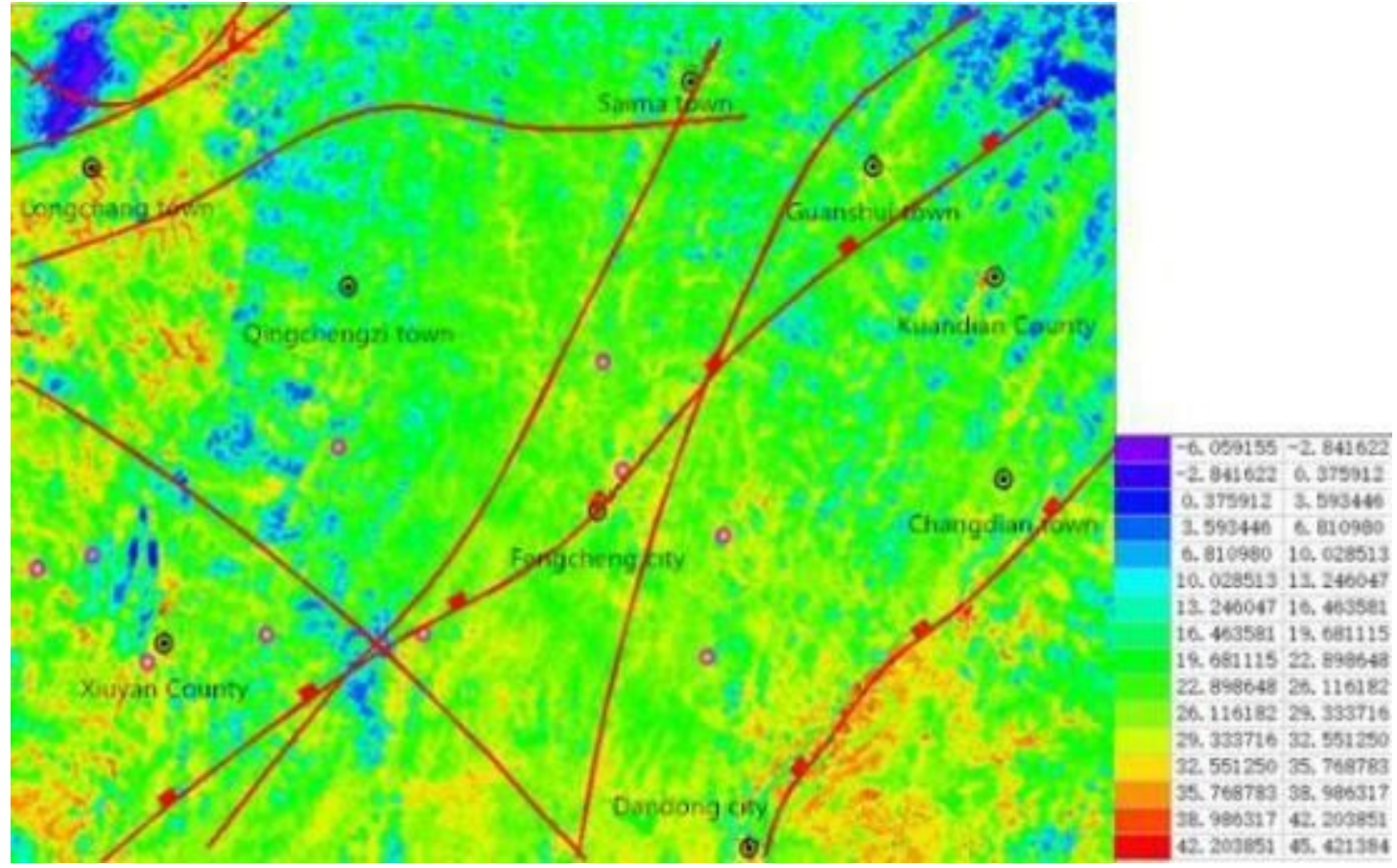

Figure 11

Map of surface temperature retrieval results on Jul. 13, 2014. 


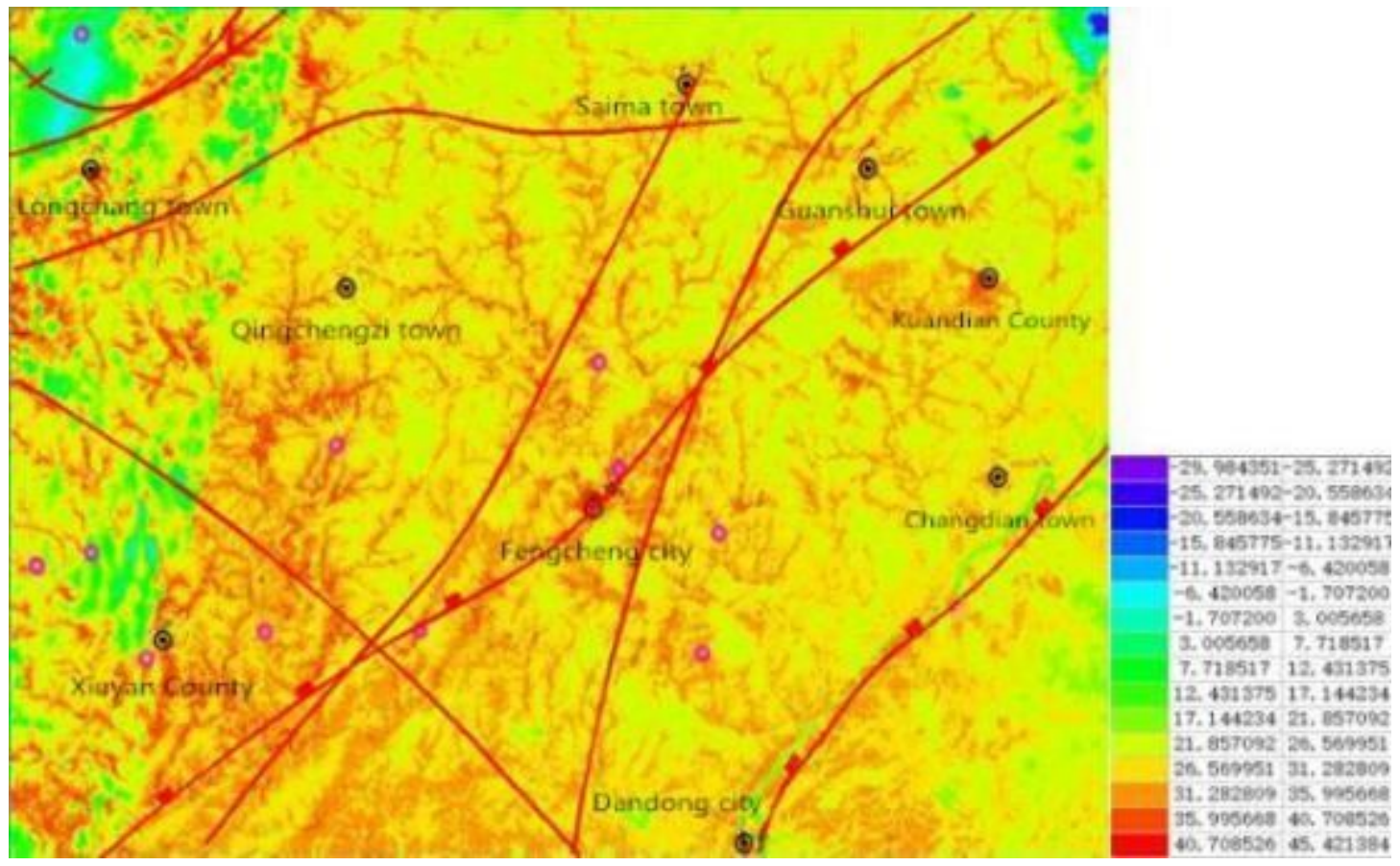

Figure 12

Map of surface temperature retrieval results on May. 28, 2014.

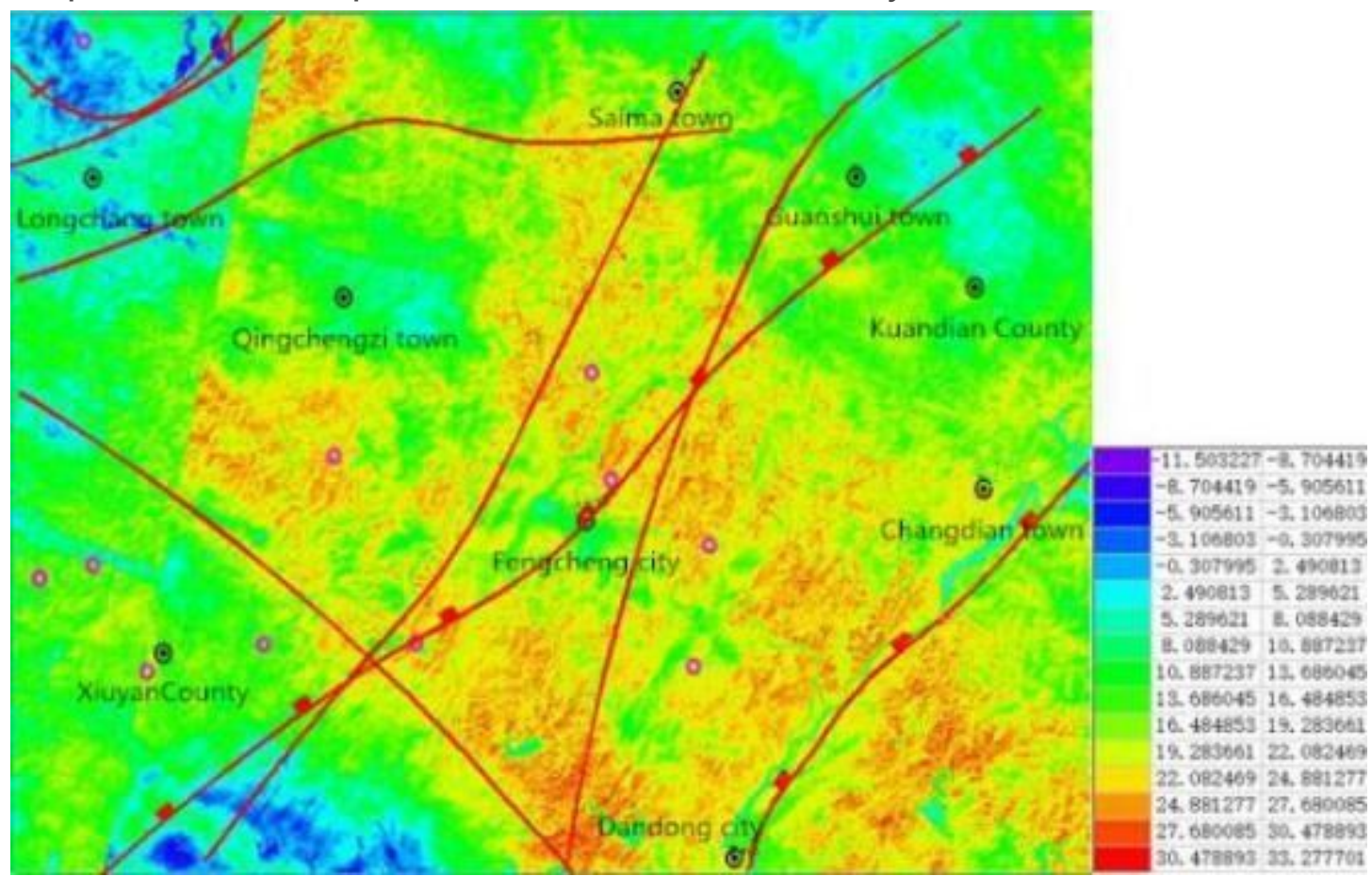

Figure 13

Map of surface temperature retrieval results on Apr. 10, 2014. 


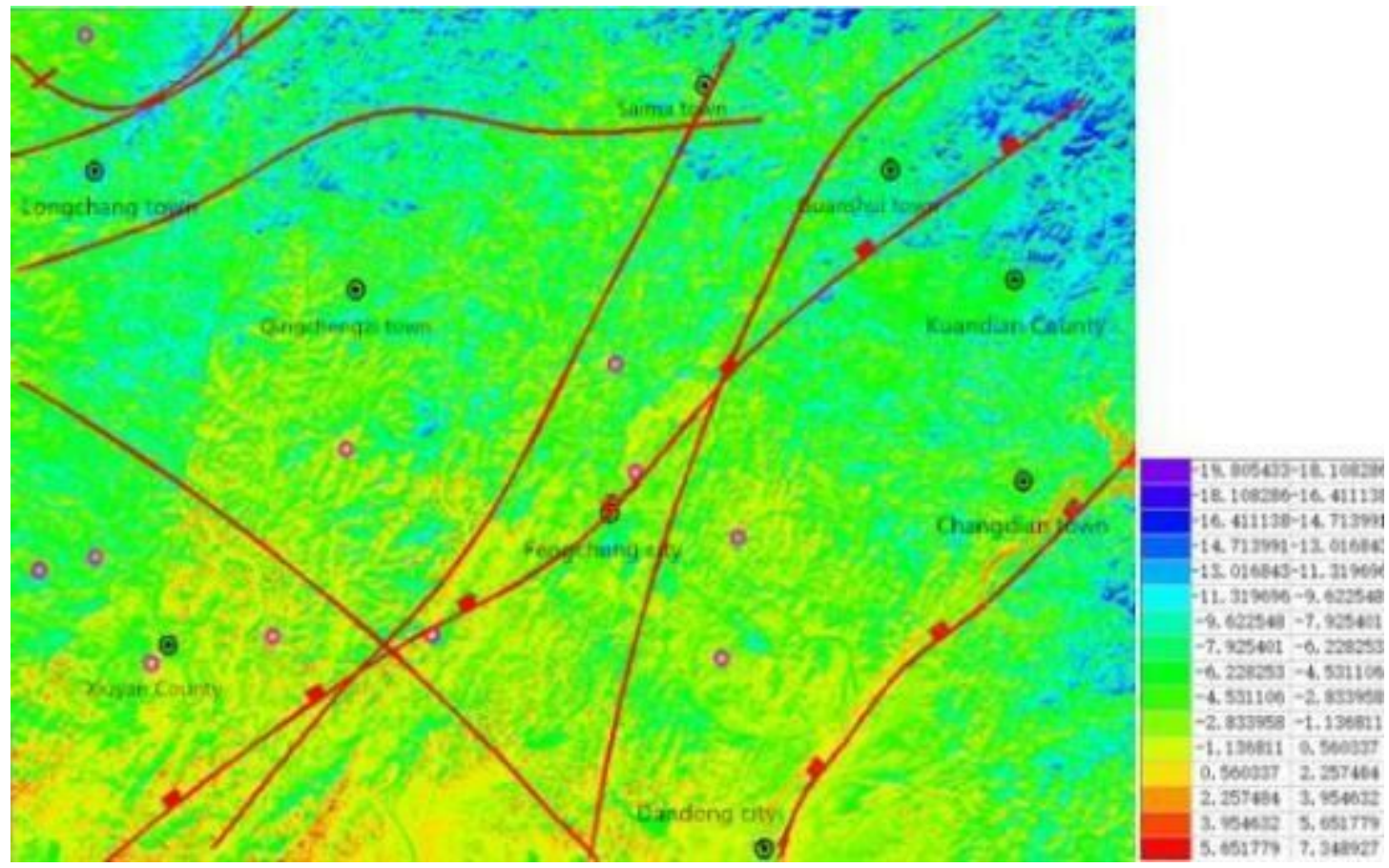

Figure 14

Map of surface temperature retrieval results on Jan. 4, 2014. 


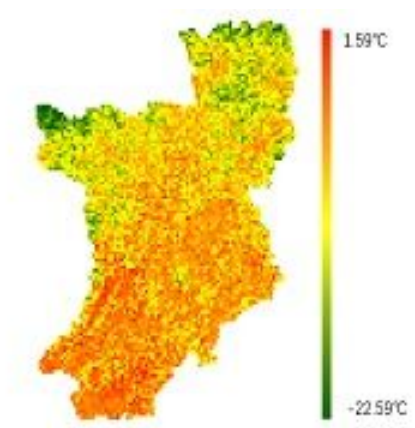

resulting image on Dec. 6, 2014

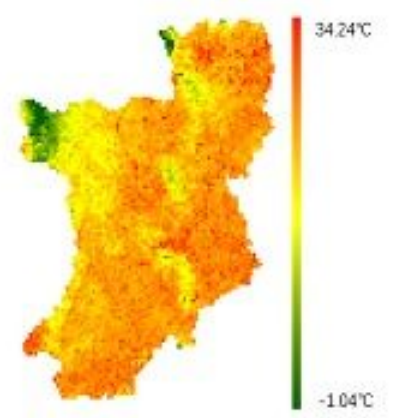

resulting image on Sept. 1,2014

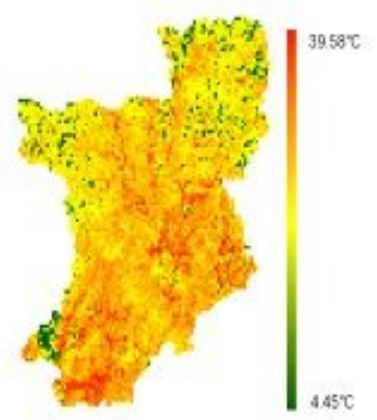

resulting image on Jun. 13, 2014

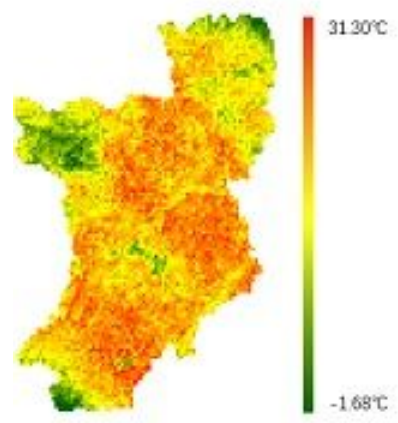

resulting image on A pr. 10, 2014

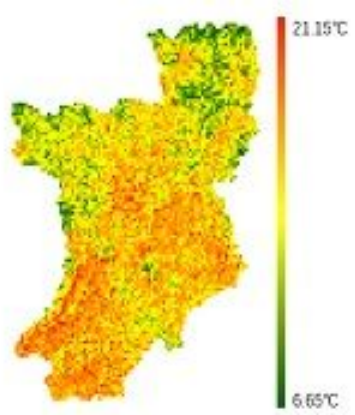

resulting image on Oct. 3, 2014

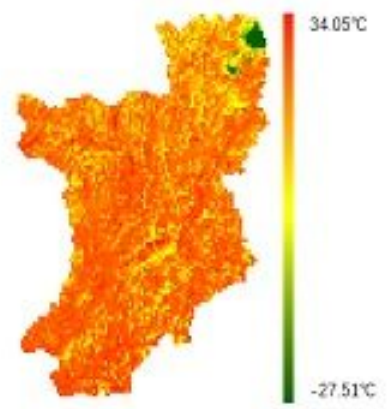

resulting image on Aug. 16, 2014

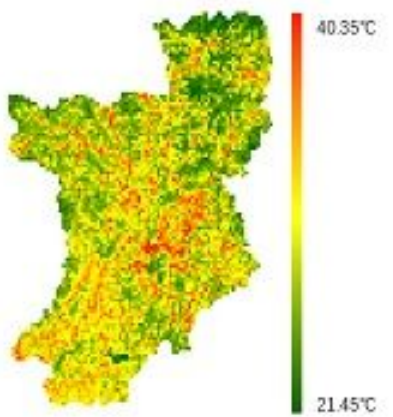

resulting image on May. 28, 2014

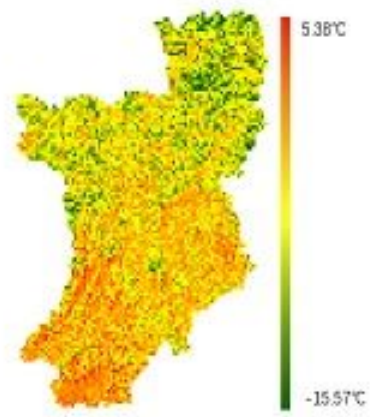

resulting image on Jan. 4,2014.

\section{Figure 15}

Land surface temperature retrieval results of Fengcheng City in each month of 2014. 

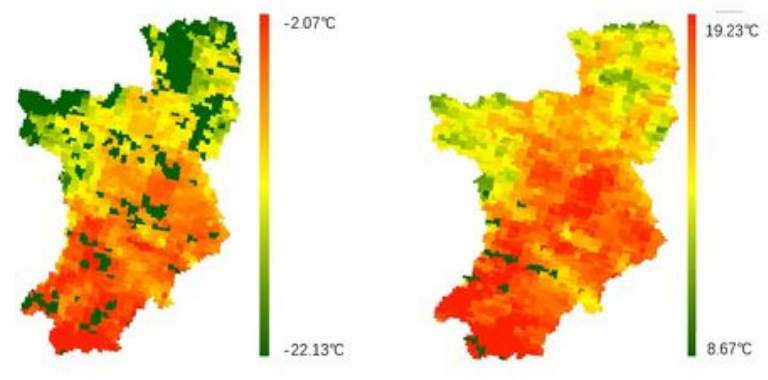

reviltrng ungeen Dec. 6,2014
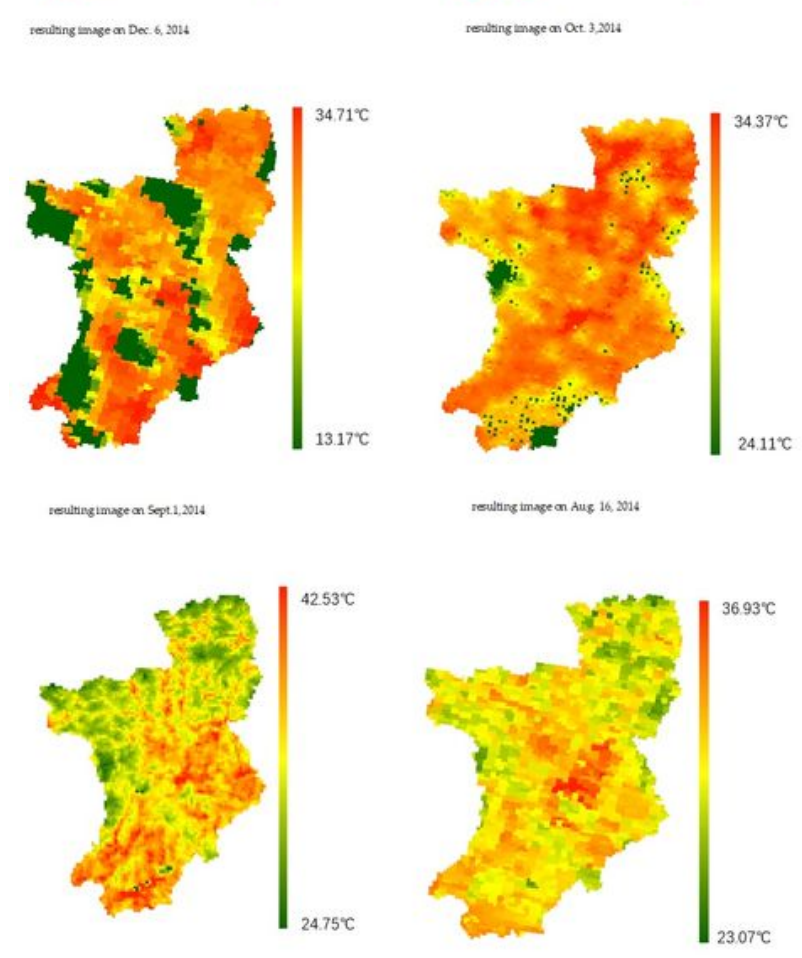

iscultrg imase an lun 13,2014
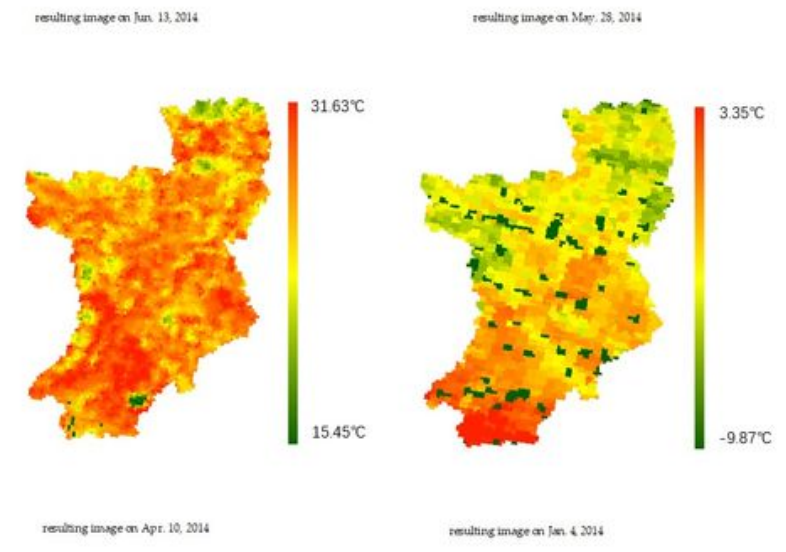

Figure 16

Processing of the MODIS LST data of Fengcheng City in each month of 2014. 